\title{
Actions Speak Louder than Words: How Figurative Language and Gesturing in Entrepreneurial Pitches Influences Investment Judgments
}

DOI:

10.5465/amj.2016.1008

\section{Document Version}

Accepted author manuscript

Link to publication record in Manchester Research Explorer

Citation for published version (APA):

Healey, M., Clarke, J., \& Cornelissen, J. (2018). Actions Speak Louder than Words: How Figurative Language and Gesturing in Entrepreneurial Pitches Influences Investment Judgments. Academy of Management Journal, 62(2), 335-360. https://doi.org/10.5465/amj.2016.1008

Published in:

Academy of Management Journal

\section{Citing this paper}

Please note that where the full-text provided on Manchester Research Explorer is the Author Accepted Manuscript or Proof version this may differ from the final Published version. If citing, it is advised that you check and use the publisher's definitive version.

\section{General rights}

Copyright and moral rights for the publications made accessible in the Research Explorer are retained by the authors and/or other copyright owners and it is a condition of accessing publications that users recognise and abide by the legal requirements associated with these rights.

\section{Takedown policy}

If you believe that this document breaches copyright please refer to the University of Manchester's Takedown Procedures [http://man.ac.uk/04Y6Bo] or contact uml.scholarlycommunications@manchester.ac.uk providing relevant details, so we can investigate your claim.

\section{OPEN ACCESS}




\section{MACADEMY OF Management \\ Journal}

\section{Actions Speak Louder than Words: How Figurative Language and Gesturing in Entrepreneurial Pitches Influences Investment Judgments}

\begin{tabular}{|c|l|}
\hline Journal: & Academy of Management Journal \\
\hline Manuscript ID & AMJ-2016-1008.R3 \\
\hline Menuscript Type: & Revision \\
\hline Keywords: & $\begin{array}{l}\text { Entrepreneurship (General) < Entrepreneurship < Topic Areas, Lab } \\
\text { experiment < Quantitative Orientation < Research Methods, Qualitative } \\
\text { orientation (General) < Qualitative Orientation < Research Methods }\end{array}$ \\
\hline Abstract: & $\begin{array}{l}\text { A key challenge for entrepreneurs is to convince investors of their business } \\
\text { ideas in a pitch. Although scholars have started to explore how } \\
\text { entrepreneurs convey their passion and preparedness in a pitch, they have } \\
\text { overlooked the possible variation that exists in the verbal and nonverbal } \\
\text { expressions of entrepreneurs. We build on research in cognitive science } \\
\text { and entrepreneurship to examine the nature and influence of specific forms } \\
\text { of speech and gesturing used by entrepreneurs when pitching. In an initial } \\
\text { qualitative field study we identify distinct pitching strategies entrepreneurs } \\
\text { use, involving different combinations of verbal tactics (using literal and } \\
\text { figurative language to frame a venture) and gesture (using different types } \\
\text { of hand gestures to emphasize parts of their pitch and convey product and } \\
\text { venture ideas). In an experimental study with samples of investors and } \\
\text { students, we examine the impact of these strategies on the propensity to } \\
\text { invest. We found that although variation in the type of language } \\
\text { entrepreneurs used had limited effects, using gestures to depict and } \\
\text { symbolize business ideas had strong positive effects. Our findings indicate } \\
\text { that the skilled use of gestures by entrepreneurs helps potential investors } \\
\text { imagine aspects of a new venture for themselves, enhancing perception of } \\
\text { its investment potential. }\end{array}$ \\
\hline
\end{tabular}




\title{
Actions Speak Louder than Words: How Figurative Language and Gesturing in Entrepreneurial Pitches Influences Investment Judgments
}

\author{
Jean S. Clarke \\ Emlyon Business School \\ France \\ clarke@em-lyon.com \\ Joep P. Cornelissen \\ Erasmus University \\ Netherlands \\ Cornelissen@rsm.nl \\ Mark P. Healey \\ University of Manchester \\ United Kingdom \\ mark.healey@manchester.ac.uk
}

Acknowledgements: All authors contributed equally to this article. We are especially appreciative of the guidance of associate editor Kevin Steensma and our three anonymous reviewers. This research was funded by the Economic and Social Research Council (grant number ES/K00185X/). We also thank Yorkshire Forward who generously supported the data collection for the first study and Manchester Business Growth Hub for their assistance with data collection for study 2. We are also grateful to seminar participants at EMLyon, Boston College and the University of Amsterdam for their helpful feedback and comments on earlier versions of this paper. 


\title{
ACTIONS SPEAK LOUDER THAN WORDS: HOW FIGURATIVE LANGUAGE AND GESTURING IN ENTREPRENEURIAL PITCHES INFLUENCES INVESTMENT JUDGMENTS
}

\begin{abstract}
A key challenge for entrepreneurs is to convince investors of their business ideas in a pitch. Although scholars have started to explore how entrepreneurs convey their passion and preparedness in a pitch, they have overlooked the possible variation that exists in the verbal and nonverbal expressions of entrepreneurs. We build on research in cognitive science and entrepreneurship to examine the nature and influence of specific forms of speech and gesturing used by entrepreneurs when pitching. In an initial qualitative field study we identify distinct pitching strategies entrepreneurs use, involving different combinations of verbal tactics (i.e., using literal and figurative language to frame a venture) and gesture (i.e., using different types of hand gestures to emphasize parts of their pitch and convey product and venture ideas). In a subsequent experimental study with samples of investors and students, we examine the impact of these strategies on the propensity to invest. We found that although variation in the type of language used by an entrepreneur had limited effects, using gestures to depict and symbolize business ideas had strong positive effects. Our findings indicate that the skilled use of gestures by entrepreneurs helps potential investors imagine aspects of a new venture for themselves, thereby enhancing perception of its investment potential.
\end{abstract}

Keywords: entrepreneurship, pitch, passion, impression management, persuasion

Being able to deliver a successful pitch is a daunting challenge for many entrepreneurs and we are only beginning to understand why and how entrepreneurs are able to convince investors to support their burgeoning ventures. The communication process between pitching entrepreneurs and evaluating investors is one that is marked by high levels of uncertainty. For the entrepreneur, the challenge is to make the venture appear legitimate and real in order to secure the necessary funding (Aldrich \& Fiol, 1994). For the investor, she or he has to make an assessment of its feasibility (“will this work?”, “will anyone use this?”) and future earning potential. Investors will base such assessments on market and financial data, but also rely on explicit as well as more subtle social and symbolic cues that they glean from a pitch (Zott \& Huy, 2007). Such cues may involve the quality of the entrepreneur's storytelling, which facilitates their sensemaking about an investment opportunity (Martens, Jennings \& Jennings, 
2007). Other signals that investors may look out for are indications of an entrepreneur's preparedness or commitment, which fosters intuitions about the personal abilities of the entrepreneur behind the venture (Huang \& Pearce, 2015). Yet other cues are animated nonverbal displays such as frequent gesturing and facial expressions, which to investors may convey the passion of an entrepreneur to commit her- or himself to a venture and strive to make it a success (Chen, Yao \& Kotha, 2009).

Existing work thus helps in starting to understand what matters when entrepreneurs pitch to investors, but at the same time it leaves unanswered the bigger question of what really determines the effectiveness of an entrepreneurial pitch. Research on pitching has not only been rather limited (Chen et al., 2009), but the work to date has also been quite fragmented in exploring verbal and non-verbal communication strategies in isolation (Huang \& Pearce, 2015). In contrast, in the present research we examine the nature and influence of verbal tactics and expressive bodily, non-verbal, behaviors in entrepreneurial pitching. Whilst we know from other contexts that verbal and non-verbal behaviors may be tightly coupled communication mechanisms, i.e., they are synchronized and each carries complementary but distinct meanings (Ambady \& Rosenthal, 1992; McNeill, 2005), we know little about their separate and integrated effects in the high-stakes, high-uncertainty context of entrepreneurial pitching. How do entrepreneurs combine verbal tactics and expressive non-verbal behaviors when communicating to investors? How do these two channels - alone and in combination - impact the judgments of potential investors? What are the mechanisms through which they influence investors? Our research was designed to answer these questions using a mixed methods approach.

We first develop a grounded theory of pitching strategies based on an inductive study of the variety of ways in which entrepreneurs pitched at a regional investment forum. We identify a much broader range of verbal and nonverbal forms of communication in pitches than 
acknowledged in prior research (Chen et al., 2009; Cardon et al., 2009), uncovering distinct variation in how entrepreneurs use figurative language to frame a venture and use hand gestures (i.e., movements of hands and arms that co-occur with speech) to explain and depict their products and business. We use these observations to inductively theorize how entrepreneurs combine verbal and nonverbal communication into distinct types of pitching strategies. This integrated theoretical account contributes to our understanding of how entrepreneurs pitch in real life-settings and of the natural variation that exists in their pitching strategies. We then use this emergent theory to develop and test hypotheses concerning the effectiveness of various verbal and non-verbal pitching strategies in an experimental design using samples of professional investors and students. We find strong evidence for the importance of nonverbal hand gestures in influencing investment judgments following a pitch. The findings also support our theorizing that entrepreneurial gesturing triggers mental imagery among potential investors, enabling them to envisage a product/venture and thereby enhancing perception of its investment potential.

Overall, our findings contribute to the literature in three main ways. First, the existing literature mainly views non-verbal behavior and bodily gestures as secondary behaviors that are limited to conveying an entrepreneur's passion (Chen et al., 2009; Cardon et al., 2009). We challenge this view and offer a broadened account of entrepreneurs' pitching strategies that considers non-verbal behaviors and bodily gestures as carriers of meaning as well as passion and posits them as integral to communication and persuasion. Second, prior work tends not to distinguish between the specific types of gestures entrepreneurs use when they communicate with potential investors or how they combine gestures with verbal framing (Chen et al., 2009). We extend current theory by distinguishing different forms of gestures based on their unique functions and by explicating how entrepreneurs combine them with verbal tactics to communicate and persuade. Third, we identify mental imagery - i.e., the mental imagery 
experienced by viewers of a pitch as evoked by the entrepreneur's gestures - as a key mechanism through which entrepreneurs' actions influence others' judgments of a venture's investment potential, responding to calls to understand how such actions affect investment judgments under uncertain conditions (Huang \& Pearce, 2015).

We draw on, and contribute to, two literatures in developing and testing our theory of the nature and effectiveness of entrepreneurial pitching strategies: the broad literature on rhetoric and framing in entrepreneurship and recent research on the impact of expressive behavior during pitches on investor evaluations. We first review these bodies of work to develop the ground for developing and testing our theorizing. We then go into detail on each of our studies and their findings and conclude the paper by discussing the main implications for further research.

\section{ENTREPRENEURIAL PITCHING TO INVESTORS}

The acquisition of investment is a critical step for many entrepreneurs in the early stages of their venture. Entrepreneurs, however, typically face challenges in convincing investors of their venture at that stage due to the 'liability of newness' with often little in the way of a track record, obvious asset value or profitability to show (Brush, Greene \& Hart, 2001). In this context, how entrepreneurs communicate about their ventures is crucial to convince investors and secure investment (Bird \& Schjoedt, 2009). Entrepreneurs generally use two broad categories of communication for this purpose: textual and verbal forms of communication. Textual modes of communication include executive summaries, pitch decks (i.e. short series of explanatory slides), and written business plans or IPO brochures, which are intentionally produced "texts" that can be sent to or accessed by individual investors (Giorgi \& Weber, 2015; Martens et al., 2007). Verbal communication, on the other hand, involves formal pitches and presentations to investors as well as informal conversations and meetings between entrepreneurs and investors (Huang \& Knight, 2017). The first category is a mediated form of communication, 
whereas the latter category is more inter-personal in nature, with investors judging the presentation and performance of an entrepreneur in situ. Amongst verbal forms of communication, one format, used by the majority of incubation schemes, investment meetings and entrepreneurship competitions has emerged as the "industry standard" in recent years: a 5 to 10 minutes pitch in which the entrepreneur narrates a series of slides, providing an overview of the business plan to potential investors (Brooks, Huang, Kearney \& Murray, 2014).

Such pitches are characterized by high levels of uncertainty as investors have to judge the feasibility of a venture and its future ability to generate revenue on the basis of the limited information provided in a pitch. In this context, the persuasive abilities and communication skills of entrepreneurs in a pitch are particularly crucial to shape investor preferences and investment evaluations. Prior research suggests that both what is said and how it is said by the entrepreneur appear to matter, including the way in which the contents of the business plan are framed in a compelling and familiar way (Martens et al., 2007) and how the pitch is delivered in an involved and animated manner (Chen et al., 2009). In addition, research from the side of the investor suggests that both the verbal and nonverbal cues that are given by an entrepreneur matter as well, including amongst other things the gender of the presenter (Brooks et al., 2014) and specific forms of body language and posture during the pitch (Huang \& Pearce, 2015). In what follows, we contextualize these findings by drawing on the existing entrepreneurship literature, take stock of the research to date and motivate the research questions of the current study.

\section{Framing Ventures as Investment Opportunities}

A growing body of research examines how entrepreneurs of early stage ventures can establish legitimacy and mobilize support from important stakeholders including investors and other resource providers (customers, employees) as well as from important information intermediaries (the media, public opinion leaders) by engaging in strategic communication 
activities such as verbal framing and storytelling strategies (Cornelissen \& Clarke, 2010; Garud, Schildt, \& Lant, 2014; Wry, Lounsbury, \& Glynn, 2011). These strategies are important for entrepreneurs, particularly when they help portray ventures in a positive or inclusive way or cue a familiar frame of reference that investors and other stakeholders can easily understand, relate to, and potentially support (Aldrich \& Fiol, 1994). Such communication strategies, in other words, may help individual entrepreneurs to mobilize resources (Lounsbury \& Glynn, 2001), and may in the process also facilitate the legitimating of a nascent field as a whole such as a new market or industry (Wry et al., 2011).

As an umbrella construct, framing incorporates more specific verbal strategies such as the use of analogies, metaphors and narrative storylines in entrepreneurial presentations, written texts, and other forms of communication (Lounsbury \& Glynn, 2001; Martens et al., 2007). These kinds of figurative and rhetorical forms of speech form the specific verbal tactics through which entrepreneurs are able to cue a particular frame of reference through which the venture can be understood and impose a logical structure upon equivocal happenings (Vough, Bataille, Noh \& Lee, 2015) such that "a key aspect...is their ability to reduce uncertainty" (Lounsbury \& Glynn, 2001: 549). As such, it has been argued that the use of these forms of language in entrepreneurial communication can contribute to reducing the uncertainty with which the decision to invest in a new venture is surrounded by packaging information about the venture in a more meaningful whole (Lounsbury \& Glynn, 2001), and by embedding the unfamiliar in a well-known and familiar structure (Cornelissen \& Clarke, 2010).

Whilst case studies of successful entrepreneurial activity highlight the role of strategically used language in securing investment (e.g., Navis \& Glynn, 2010; Weber, Heinze \& DeSoucey, 2008), there has been virtually no systematic research on the type of language that is used in entrepreneurial pitches, and how such language may impact investor evaluations. Prior 
theoretical work (Cornelissen \& Clarke, 2010; Garud et al., 2014) speculates that the use of specific forms of language such as the use of storylines or metaphors directly impacts investors to generate their own interpretations, such that they "are likely to gain confidence in the viability of those possibilities and in others' ability to make them a reality" (Bartel \& Garud, 2009: 112). However, such an effect cannot be assumed at the outset but instead requires detailed empirical examination. Investors are savvy and experienced professionals who may not be easily persuaded by verbal tactics alone and may attend to other tangible data and cues provided in a pitch (Huang \& Pearce, 2015). Accordingly, the first research question that we pursue in this paper is what discernible patterns of language entrepreneurs use as part of their pitch, and whether and how in turn such variation in their language affects investor evaluations.

\section{Expressive Behaviors and Investor Evaluations}

In recent years, a growing body of work within the entrepreneurship domain has accumulated around the impact of all kinds of expressive behavior - facial expressions, posture, gesture and speech - in entrepreneurial pitches on investor judgments and decision-making. Within the entrepreneurship field, this body of work is most closely associated with a specific line of research on entrepreneurial passion (Chen et al., 2009; Cardon et al., 2009). However, we here use the broader label of expressive behaviors and examine how these behaviors impact investor evaluations of a pitch (Huang \& Pearce, 2015).

Research on entrepreneurial passion has explored the question of whether the demonstrated passion of an entrepreneur in a pitch has a direct influence on investor decisionmaking (Cardon et al., 2009; Chen et al., 2009; Mitteness, Sudek \& Cardon, 2012; Pollack et al., 2012). In an influential study, Chen et al. (2009) divided the passion construct into affective and cognitive dimensions. Affective passion refers to the display of emotions, enthusiasm and energy in bodily movements, gestures and speech during a pitch. In contrast, cognitive passion - which 
Chen et al. (2009) termed preparedness - concerns the substance and understanding of the business idea that entrepreneurs communicate through the content of their pitch. In two experiments, they found that while the cognitive dimension of passion (preparedness) had a positive effect on investors' decisions, the affective dimension of passion (the entrepreneur's displayed passion) had no direct impact on investors' decisions to fund the venture or not. Research has since tried to replicate these findings, but with mixed results to date (Cardon et al., 2009; Mitteness et al., 2012; Murnieks et al., 2016). These inconsistent findings appear to suggest that we may at present not yet have the full measure of whether and how the various expressive behaviors in a pitch influence the chances of securing investment.

To illustrate this general point, an important recent study by Huang and Pearce (2015) highlights the role of subtle, expressive cues that are provided by entrepreneurs in their communication, which they argue provide crucial "glimpses" of who they are to investors. Combining an inductive qualitative study with two controlled experiments, they found that business angel investors base their investment decisions to a large extent on an intuitive "gut feel" perception of the entrepreneur alongside assessments of the business viability. Such positive person perceptions, they argue, were largely created on the back of verbal and nonverbal cues, giving investors an impression of whether the entrepreneur will be able to follow through and realize the venture's potential. Although Huang and Pearce (2015) did not directly measure or control for various forms of verbal and nonverbal communication, their study creates an opening to study expressive behaviors in a pitch and how these influence investors.

In general, expressive behaviors break down into specific, discrete verbal and nonverbal behaviors, which may combine into higher order-constructs (e.g., the display of entrepreneurial passion). Besides verbal expression, nonverbal expressives involve bodily movements (posture, gesturing, facial expressions), physical appearance (attire, attractiveness), vocal elements 
(intonation, prosody) and eye contact and gaze (Bonaccio, O'Reilly, O'Sullivan \& Chiocchio, 2016). In the present paper, we direct our attention to bodily movements, or kinesics (Bonaccio et al., 2016), as the natural non-verbal medium of communication alongside verbal speech in interpersonal communication settings such as pitches. Ambady and Rosenthal (1992) refer to the visual, nonverbal channel of communication (facial expressions and bodily movements), the verbal channel, which includes speech and transcripts, and the audiovisual channel, which combines the two. We similarly focus on these primary "channels", and their combination, in pitches, recognizing that entrepreneurs naturally move their bodies when they speak and these movements are not accidental, but, as we know from other communication contexts, are often tightly coupled to the communicative messages speakers wish to convey (see, e.g., Kelly Özyürek, \& Maris, 2010). Investors, we argue, take notice of these movements alongside the entrepreneur's speech and may, as suggested by Huang and Pearce (2015), infer different things about entrepreneurs and their messages as a result.

Accordingly, the second question that we ask in this paper is what kind of bodily movements entrepreneurs display when they pitch and whether and to what extent such movements influence potential investors. Pursuing this question allows us to identify the role and impact of nonverbal expressives. Furthermore, by addressing our two research questions together we sought to theorize and test the interplay between the verbal and non-verbal, or bodily, aspects of pitching, and how the alignment and synchronicity between these two "channels" (Ambady \& Rosenthal, 1992) may influence and persuade investors.

\section{STUDY 1}

The objective of our first study was to identify different features of speech and bodily movements that are used by entrepreneurs when they pitch. The motive for doing so was that 
where prior research has indicated the general importance of verbal and non-verbal tactics (Chen et al., 2009), these have not been clearly identified nor therefore specifically examined.

\section{Study Context}

In line with these objectives, we studied an entire cohort of seventeen independent technology entrepreneurs pitching their ideas to specialist technology investors during a regional investment forum in the North of England. Technology entrepreneurs are particularly likely to confront significant challenges in communicating their ideas to investors due to the complexity of their technologies. All 17 entrepreneurs were in the early stages of commercializing their ventures across different industries, ranging from biomedical innovations and inkjet printing to capturing green energy from tidal waves. The majority of entrepreneurs were men (14 out of 17).

Prior to the pitches, expert investment advisers had pre-screened and assessed all ventures on the basis of the viability of the technology and readiness for investment and had provided entrepreneurs with a standard pitch template to guide the overall structure of their pitches. All pitches were live recorded but in a non-obtrusive manner with cameras placed discretely at the side and back of the room. Two of the authors attended the event live, watched the presentations and made field notes of what they felt stood out for each pitch. The setting did not allow them to infer the immediate effectiveness of the pitches based on audience responses or the nature of the questions posed by the investor panel.

\section{Coding and Analysis}

After developing a preliminary sense by watching these pitches live, the same two authors undertook a more detailed analysis of each of the 17 videotaped pitches. The initial analytical approach that they took was open ended and inductive (Corbin \& Strauss, 2008) but driven by a broad interest in identifying noticeable variation in the verbal and nonverbal behavior demonstrated in each pitch. They watched each tape and following an "open coding" approach 
cycled back and forth between the data and their emergent interpretations. They then compared between themselves their initial observations of all 17 pitches and realized that the large majority of the variation on the non-verbal dimension existed primarily of gesturing, with little noticeable variation observed in facial expressions or body posturing. In the few instances where body posturing was observed, it seemed to be part of an open form of gesturing with both arms being moved outwards by the presenter. On the verbal plane, both coders similarly compared their initial observations and realized that the general variation that they had identified consisted of a broad split between the use of literal versus figurative language in the 17 pitches, with some pitches being literal and factual accounts of a product or service and its development whereas other pitches demonstrated a significant use of figurative forms of speech. Figurative speech included the use of analogies or metaphors to generally describe a business opportunity or market and the use of figurative stories or symbolic anecdotes to relay a sense of how the initial opportunity was identified.

Based on these consistent observations, the two coders decided to approach the subsequent phase of the analysis by deductively drawing on existing protocols for the coding of both gesture and figurative speech (cf. Locke, 2001). Using these protocols, the coders focused on (1) whether speech was clearly marked in terms of more figurative versus literal content, and (2) identified and annotated the gestures that were used throughout each pitch. We then calculated the reliability of the coding based on a sample of 5 pitches. If codes were assigned at random, alpha would take the value of 0 ; if agreement was complete, alpha would take the value of 1 . The alpha coefficient was 0.85 for the coding of the figurative language and 0.90 for the gesture coding, indicating a robust coding scheme (Carletta, 1996).

1. The analysis of speech involved systematically identifying the use of figurative versus more literal language in a pitch to identify the "framing" used by each of the entrepreneurs. We 


\footnotetext{
${ }^{1}$ Following conventions from corpus linguistics (Deignan, 2005), frequency is calculated as a percentage for each transcribed text and its total length. The banding of frequency figures across the 17 texts was done inductively (Moon, 1998) based on observed differences. In this respect it is important to note that entrepreneurial discourse is not a highly conventionalized discourse that is fully structured by fixed expressions and conventional idioms (Moon, 1998). Individual entrepreneurs can thus choose to use either literal or figurative expressions when they are pitching, as demonstrated by our data. This furthermore means that any noticeable increase in figurative language that is observed is significant, marking a distinct pattern in speech.
} 
entrepreneur's hands in each gesture was then described, initially without sound to ensure the initial gesture coding is not influenced by the analysis of the speech (Congdon, Novack \& Goldin-Meadow, 2018). Following this initial coding, both coders then revisited their annotation whilst listening to the speech, sharpening their interpretations and also highlighting instances where speech and gesture synchronized and aligned. The gestures were then categorized into ideational gestures, which depict semantic information, or beat gestures, which mark points of emphasis in speech but "do not present a discernible meaning” (McNeill, 1992: 80) (see Table 1 below). Ideational gestures were further subdivided into gestures used in an ideational metaphoric way to refer to an abstract notion in terms of a physical form or movement (Kendon, 2004) and gestures used to refer to a concrete referent namely iconic (reproduces the form of a physical object being spoken about) or deictic (speaker points to objects physically present or objects alluded to in the accompanying speech). Table 1 provides an overview of the frequency and type of gesturing across the 17 cases. $^{2}$

After the full coding of the data in this manner, we conducted axial coding (following Corbin \& Strauss, 2008) to relate our emerging findings about the nature of the different patterns in pitching that we found whilst consulting theoretical precedents that might help explain what was being uncovered. The end result of this final stage was a conceptualization of four distinct pitching strategies as inferred from the verbal and non-verbal coding of the 17 pitches.

\footnotetext{
${ }^{2}$ The frequency of gesturing was calculated based on the number of gestures used per minute, in line with protocols from cognitive science (McNeill, 2005). There is no single baseline for determining whether the frequency of gesturing is high or low (for example, the speed of talking may influence the rate of gesturing). However, a standard baseline of around 4 gestures per minute is often maintained for natural conversations (McNeill, 2005). Informed by this standard, we subsequently inductively banded the frequency of gesturing into low versus high levels of gesturing and identified based on the type and frequency of gesturing distinct pitching strategies.
} 


\section{Results and Discussion}

The coding and analysis of the 17 pitches demonstrated significant variety in the frequency and variety of figurative language across the pitches (see Table 1). A number of pitches involved very little figurative language and rather involved literal and technical descriptions of the technology. Other pitches involved a frequent and repetitive usage of figurative language, interspersed with more literal descriptions of the technology.

In a majority of cases, the figurative language that was used was rather incidental and limited to common figurative business idioms that refer to the positioning of the venture in the market and its potential for growth. In these cases, figurative language was not used to describe the core of the technological product, describing its function or value, but was limited to idiomatic expressions that charted the overall development of the venture. Almost all entrepreneurs used common business idioms around their current "position" in the market and the "exit" point that they were aiming for. For example, the entrepreneur from Cloud Accounts, which offers "cloud-based" accounting software as an alternative to traditional offline accounting procedures, outlined their current position and exit strategy as follows (note:

following linguistic conventions, figurative language is underlined);

"Brand awareness is our biggest barrier to achieving our targets and our potential. From an exit strategy point of view we would be potentially looking at a trade sale or maybe floating on AIM [a sub-market of the London Stock Exchange for smaller growing companies]. We've got a fantastic business proposition so if you would like to come and speak to us then see us in the stand outside, I've got some of my guys with me; I think you'll realize we're good at communication."

Such a specific and limited use of business idioms contrasts with the use of analogies and metaphors in other cases where they are centrally used to depict the basic functioning of the technology and the products or services that it gives rise to. In these cases, the use of figurative language is high and present throughout the pitch, from start to finish - whereas the use of business idioms is limited to the front end and the back end of the pitch where the potential for 
growth and financial projections are being discussed. For example, the entrepreneur of Power

Tidal, a green energy company that captures and resells energy from tidal waves, explains the basic technology of his company through a series of analogies and metaphors;

"Twin submerged horizontal foils or blades present an angle into the flow and are driven up or down by the movement of the water across their surface. And this is completely analogous to the way that an airplane wing provides lift. This unique approach to capturing tidal power energy is different from all of the other technologies around. As you can see they're all based on rotating devices, which we would class as underwater windmills if you like. And we believe that our approach is fundamentally more suited to the challenges faced by tidal power".

Here the entrepreneur analogically employs established technologies to explain the novel technology of wave and tidal energy. By providing the listener with analogous examples of technologies they already understand (e.g., windmills, airplanes), the listener is better able to grasp the basic elements of the new technology and form a clearer understanding of the venture.

At the gesture level, we similarly observed considerable variety in the frequency of gesturing and in the types of gestures that were used as part of a pitch. In a number of pitches, entrepreneurs used little or no gesturing at all. In other instances, entrepreneurs supplemented beat gestures with frequent ideational gestures to symbolize their ideas for their audience.

For example, the entrepreneur of Smart Rheology, which develops instruments for the rheology market, used an extensive number of beats throughout his presentation alongside a very small number of ideational gestures. The beat gestures consisted of his right hand flapping up and down just above waist height with his palm opened toward the ceiling. This gesturing had no specific meaning and was not noticeably tied to any points of emphasis in his accompanying speech. In this case, his gesturing may have been a way of structuring his own thinking whilst speaking (McNeill, 1992). In other cases the entrepreneurs used beats to emphasize certain points in their speech. For example the entrepreneur from Life Tech for the most part of his presentation rested his hands either on the lectern or placed them behind his back. He used only a 
small number of 'beat' gestures throughout to mark the rhythm of his speech and in an attempt to seemingly engage his audience.

In contrast, the entrepreneur representing Organ Solutions, a company that develops solutions to preserve transplant organs, used a high number of both beat and ideational gestures (including iconic and metaphorical gestures). Iconic gestures that she used included using her index finger alongside her thumb to highlight and "capture" the distinctive properties of the solution compared to competitors. In doing so, the entrepreneur objectifies the difference with the competition. The entrepreneur also used a series of metaphorical gestures including a constant rolling movement, with both hands clasped in front of her body and tilted inward towards each other, and with both arms then rotated outwards to indicate the progress that the company has made since its inception. She also on a number of occasions moves her right hand, palm down, upwards vertically (a so- called "more is up" metaphorical gesture, see Lakoff \& Johnson, 1980) to symbolize the fact that her company's organ transplant solution allows organs to be preserved for twice as long compared to rival products.

In identifying these different uses of gestures (see Table 1), we draw attention to the difference between "hand gestures such as 'beats', meaningless forms of hand movements that are used to increase the prominence of certain aspects of speech or regulate interactions" (Özyürek, 2014: 2) and ideational gestures that signify and convey meaning through "perceptual, motoric and analogic mappings that can be drawn between gestures and the conceptual content they evoke" (Wu \& Coulson, 2011: 184). This difference is, we argue, instructive as these gestures play different roles in pitching and may on that basis, as we argue below, impact investor evaluations differently. This difference has, however, not been recognized in prior research with different gestures being confounded in a composite factor and with the ideational role of gesturing being neglected (Chen et al., 2009; Cardon et al., 2009). 
Combining the analysis of the language and gestures used by entrepreneurs, we can identify four distinct styles of pitching, as highlighted in Table 1. The first, which we label as a "literal" approach, involves a low level of figurative language and a negligible use of gestures. The emphasis in this approach is on persuading investors through a literal, technical and fact-like description of a venture. This approach is common across the 17 cases (six cases). An example of this "literal" approach is Cloud Accounts, which as described above provides "cloud-based" accounting software. The entrepreneur stood throughout the presentation with his hands in his trouser pockets and relied on factual statements about the opportunity he presented. For example he highlights that with the company they "now have over fifty accountants signed up... and not only have [these accountants] bought in to sell to their clients, they are now using [this online system] to do their own books". He also stresses that all members of the venture team are "professionally qualified with a wealth of experience in many areas ranging from accounting, marketing, sales, to business development". Instead of evoking figurative language, the emphasis is on persuasion through appeals to their experience, professionalism and expert knowledge.

The second approach we term the "rhetorical" approach and involves a high level of figurative language to frame the venture, but with very little gesturing. The emphasis in this instance is on convincing investors purely on the strength of one's figurative speech. This approach was evident in just two cases. The entrepreneur from In Vitro Testing for example illustrates this approach; he stood in a stationary position throughout the presentation with his left hand in his pocket and his right hand resting on the lectern and used very few gestures. His speech, however, was littered with figurative language. The venture provides an alternative to testing pharmaceutical drugs on animals by allowing pharmaceutical companies to test the impacts of drugs on cultured cells using bioreactor technology. In his pitch, he constantly used the analogy of the functioning of the human body to explain how the technology worked; "what 
we've got is a system that's analogous to the human body. If you look at the details you see that we've got multiple chambers and they're interconnected and we have flowing media going round our system so it's like the blood flowing through the body through the different organs". Furthermore, to persuade investors he uses a metaphor of physical size to express the market opportunity with phrases such as "just to give you a feel of how enormous this market is" and “some estimates say that [there] will be an additional eight million animal tests needed, so that's the scale of the problem".

The third, "demonstrative" approach, involves hardly any or no use of figurative language, but relies on an animated delivery through a repetitive use of gestures, including beats to mark and punctuate one's speech and to engage the audience and ideational gestures that provide concrete imagery to understand a venture and its product(s). This approach was used in five out of the 17 cases. A case that represents this approach is Safe Skins, a company that designs and manufactures antibacterial door-levers and door-handles for use in hospital settings to prevent infection. The entrepreneur representing this company used gestures throughout, combining beat gestures (e.g. his right hand with the palm facing upward move up and down or side to side when emphasizing important points) and ideational gestures to help provide the audience with a visual representation of the properties of the product. In order to explain how the product works he outlines that "we have an injection molded holster which attaches directly onto the door handle so whether or not it be push pads, door levers or a pull handle this will actually be retrofitted onto the door". Accompanying this speech is a series of complementary gestures to illustrate how the product works; with his right hand he imitates pushing down a door lever by making a fist and rotating the fist in a downward motion, and then, using the same fist, he makes a pulling movement towards himself as if opening a door. 
The fourth and final "integrative" approach involves a high use of both figurative speech and gestures, including the use of ideational gestures that when aligned with figurative speech form an audiovisual 'ensemble' (Kendon, 2004) that is used to convince an audience. This approach is used in four cases in our sample. The entrepreneur representing Organ Solutions is an example of this approach. While explaining that their competitors' organ preservations solutions "provide only a very narrow window of opportunity with respect to the amount of time it takes for the organ to degenerate beyond use", the entrepreneur visually represents this narrow metaphorical "window" by bringing both hands to stomach height with fingers pointing out towards the audience and palms facing each other about a waist width apart and then pushes them slightly toward each other. This hand movement physically illustrates the short period of time that competitors' solutions retain the viability of an organ, compared to the much longer period of time provided by the technology offered by Organ Solutions.

Overall, Study 1 provides an inductive overview of how entrepreneurs in naturalistic settings use different types of gestures and figurative speech when pitching their ventures to potential investors. The typology that emerges from the findings raises important questions concerning which of these approaches is more likely to be effective in persuading investors to invest in a venture. These questions arise directly from Study 1 but also align with prior entrepreneurship research. For example, the "rhetorical" approach has been promoted as an effective approach in much prior work (e.g., Van Werven, Bouwmeester \& Cornelissen, 2015); however, Study 1 demonstrated only limited use of this strategy. When put to the test, the "rhetorical" approach may actually turn out to be less persuasive than an embodied “demonstrative" strategy involving an animated use of gestures (Chen et al., 2009). Furthermore, it may well be that analogous to other communicative situations, pitches gain in persuasive 
strength when they "integrate" the representation of ideas in speech and gesture, such that they operate as a 'composite signal' (Clark, 1996) or an 'integrated system' (McNeill, 1992).

To answer these questions, it was important to use a method that would permit valid causal inferences concerning the effects of figurative language and gesturing. For this reason, we conducted a second study using an experimental design.

\section{STUDY 2}

In Study 1, we identified distinct pitching styles based on noticeable variation in the use of figurative language and gesturing. For Study 2, we extend the identified styles into a series of hypotheses to theorize and test whether using a particular style of pitching influences others' willingness to invest in a venture. For this theorization, we draw on additional sources from entrepreneurship and cognitive science research to build up the theoretical support for the predicted effects around each style and to inform our theorizing concerning potential mediators.

In Study 1 we found that some entrepreneurs adopt an approach of concentrating on the rhetorical strength of the language that they use in their pitch. The adoption of this style rests on the assumption that a pitch is more likely to be persuasive when it includes classical rhetorical virtues such as anecdotes (personal stories) and centrally used figures of speech (metaphor and analogy) that frame a venture in familiar and oftentimes more concrete terms and therefore make it more easily understood. The targeted use of such figurative language may make "the unfamiliar familiar" (Lounsbury \& Glynn, 2001: 549), disambiguating the overall understanding of the venture in the minds of possible investors.

The high levels of uncertainty that exist in the eyes of investors concerning the market potential and future earnings of a venture at the stage of pitching (Brooks et al., 2014) may arguably heighten the effectiveness of such rhetorical tactics in helping investors to instantly form an understanding of the venture and its product or service. We thus hypothesize that 
entrepreneurs who use a high level of figurative language - by which we mean the frequent use of personal anecdotes, analogies, and metaphors - throughout their pitch are more likely to make their venture understood by investors, compared to predominantly using literal and non-descript language in a pitch. In turn, we expect that ceteris paribus investors are more likely to consider such ventures as investment targets.

Hypothesis 1: When entrepreneurs use a high (versus low) level of figurative language when pitching their business, people will be more inclined to invest.

Chen et al. (2009) argued that gesturing in a pitch has a positive effect on persuading investors, because gesture communicates affective passion to investors. However, in two studies they failed to find empirical support for this thesis. Our findings in Study 1 suggest a possible explanation for this null finding; namely, that gesturing communicates more than passion. Whereas previous research in entrepreneurship has not differentiated the functions of different types of gesture, we distinguished two main forms of gestures used by entrepreneurs - namely, beat gestures and ideational gestures (McNeill, 2005) - and observed that entrepreneurs frequently use ideational gestures in their pitches. Where beat gestures mark the rhythm of an entrepreneur's speech and provide emphasis, gestures that are used in an ideational manner symbolize abstract ideas associated with the business or demonstrate the features of a product or a service in use. Such ideational gestures in particular may provide investors with direct visual information about a product or service and about the venture, consistent with findings in psychology and cognitive science where gestures have been found to convey meanings as a separate "channel” on its own alongside speech (Ambady \& Rosenthal, 1992; McNeill, 2005).

We accordingly theorize that when entrepreneurs gesture frequently and combine numerous beat and ideational gestures in the delivery of their pitch - which we refer to as a high level of gesturing - potential investors are able to form a clearer idea of the product and of the business. The enhanced understanding that this creates in the minds of investors positively 
influences their propensity to invest in the venture, as compared to pitches that are delivered with a lower level of gesturing where such gestures are largely absent.

Hypothesis 2: When entrepreneurs use a high (versus low) level of gesturing to emphasize and depict their ideas when pitching their business, people will be more inclined to invest.

Hypotheses 1 and 2 concern the separate (i.e., main) effects of figurative language and gesture, as separate expressive "channels" (Ambady \& Rosenthal, 1992). However, the findings of Study 1 show that entrepreneurs can also combine figurative language and gesture when pitching to potential investors (i.e., the "integrated" approach). As highlighted, such combinations may consist of a synchronous reference in figurative language and in an ideational gesture, such that both converge and reinforce the same idea. The excerpts of the pitch of Organ Solutions in Study 1 demonstrate such synchronicity as part of an "integrated" delivery.

Informed by the findings of Study 1, we argue that an alignment between figurative language and gesture may create a more effective pitch, with both channels of communication being used to depict the venture and its product or service and reinforcing the same underlying idea. In the high-stakes, high-uncertainty context of entrepreneurial pitching, individual investors may also be particularly focused on how various verbal and nonverbal cues in a pitch combine in order to form an integrated "audiovisual" assessment of a business opportunity and of the entrepreneur (Huang \& Pearce, 2015). We thus suggest that the co-alignment of figurative language and gesturing in a pitch might provide a clearer depiction as well as reinforce key messages about the business, thereby augmenting investors' ability to picture the business and to form a clear sense of the opportunity. Investors will then be more likely to invest, compared to pitches that rely on the expressive force of these verbal and non-verbal "channels" separately. 
Hypothesis 3: There will be a significant interaction effect between figurative language and gesture on the propensity to invest; specifically, individuals will be more inclined to invest in a venture when entrepreneurs use a high (versus low) level of figurative language, combined with a high (versus low) level of gesturing to emphasize and depict their ideas when pitching their business.

By revealing how pitching entrepreneurs use ideational gestures, Study 1 suggested an intriguing alternative mechanism through which gesturing might influence viewers; namely, by helping them to better imagine and vicariously experience the products and ventures described in a pitch. Building on this finding, we propose that effective gesturing by an entrepreneur can evoke mental imagery among viewers, allowing potential investors to form a clearer and more concrete image of how the product works and of how the venture is likely to evolve. This mechanism constitutes an alternative pathway to persuading investors, beyond communicating passion (Cardon et al., 2009; Chen et al., 2009; Murnieks Mosakowski \& Cardon, 2014).

Our underlying explanation for how gesturing works in this context builds on research in cognitive science showing that gestures are a form of simulated action (Hostetter \& Alibali, 2008). When people think about an object or idea, such as a product or venture, they use mental imagery to simulate perceptions and actions associated with that object and use gestures to describe their mental images (Hostetter \& Alibali, 2008). Such gesture based mental simulation helps them manipulate symbols in their own minds when solving problems (Chu \& Kita, 2011) as well as communicate those symbols to others (Goldin-Meadow, 1999). Viewers who in turn see and understand a speaker's gestures are triggered to mentally simulate, through mental imagery, the underlying perceptual and motor processes for themselves (Alibali, Boncoddo \& Hostetter, 2014), incorporating this information into their own representations of the object in order to evaluate and interact with that object (Cook \& Tanenhaus, 2009).

We theorize that investors who see an entrepreneur's hand gestures simulating the features of a product (e.g., its physical characteristics, its workings, its benefits) or of the venture 
and its market (e.g., its growth, maturity) can better imagine those characteristics for themselves, enabling them to mentally simulate what the product or market looks like, how it makes one feel, and what it is like to touch or use a product. Gestures may thus be an important means by which entrepreneurs mitigate investors' cognitive uncertainty about a product and venture (Navis \& Glynn, 2011), enabling them to vicariously imagine, via an entrepreneur's bodily demonstrations, how products and businesses work and making them seem more tangible and 'real'. We thus predict that when an entrepreneur's gestures evoke such mental imagery among potential investors, they will be more inclined to invest in the venture depicted.

Hypothesis 4: The degree to which gestures evoke mental imagery among potential investors mediates the effect of an entrepreneur's gestures on the propensity to invest.

\section{Research Design}

To test our hypotheses, we conducted an experiment in which participants evaluated an entrepreneur pitching a new venture. Using an experiment enabled us to control the types and levels of figurative language and gesturing used by the entrepreneur. Moreover, because an experimental design permits robust causal inferences (Shaddish, Cook \& Campbell, 2002) it enabled us to assess with confidence whether variations in figurative language and gesturing actually cause different reactions among potential investors. We employed a 2 (figurative language: high, low) $\times 2$ (gesture: high, low) between subjects design and randomly assigned participants to one of the four treatment groups.

\section{Participants and Procedure}

We conducted our experiment with samples of professional investors (sample 1) and business students (sample 2). By replicating our study using the same design and measures but with a different population, we provide a test of empirical generalization (Tsang \& Kwan, 1999). Empirical generalization helps to set the empirical foundations of a theory, which aids 
subsequent theory development and knowledge accumulation (Tsang \& Kwan, 1999), and provides a more robust basis for providing practical advice (Bettis, Helfat \& Shaver, 2016).

Sample 1 comprised 124 investors with significant experience investing in new ventures. We recruited these investors by attending national events organized for investors (http://venturefestnetwork.com) and by contacting investors via email through links with a regional investment hub in Manchester, UK. The average age of investors was $51.38(\mathrm{SD}=$ $13.18)$ and 80 per cent were men. Investors had an average of 28.7 years work experience $(\mathrm{SD}=$ $12.37)$ and an average of 12.32 years $(\mathrm{SD}=13.89)$ experience investing in new ventures. Thirty five per cent identified as personal investors, $28.3 \%$ were angel investors, $21.7 \%$ were organizational investors, $11.7 \%$ were venture capitalists and $3.3 \%$ were peer-to-peer/crowd funding investors. Investors had made an average of 5.4 investments $(\mathrm{SD}=4.54, \min .=2$, $\max$. $=20$ ). They were also very experienced in evaluating investment opportunities presented to them, having evaluated an average of 57.3 pitches $(\min .=3$, max. $=300)$. We checked for response differences between those recruited in person $(n=65)$ and those recruited by email $(n=59)$; the two groups did not differ significantly in their evaluations of the pitches.

Sample 2 comprised 180 business students from a large UK university. Previous research on entrepreneurial pitching has used professional investors and nonprofessional evaluators to establish the generalizability of the persuasiveness of different types of pitches (Brooks et al., 2014). Research in finance also suggests that students can be a useful proxy for investors (Libby, Bloomfield \& Nelson, 2002), particularly when the complexity of the task is not high (i.e., does not require the integration of complex technical knowledge; see Elliott, Hodge, Kennedy \& Pronk, 2007). To the extent that our manipulations of figurative language and gesturing represent fundamental features of human communication rather than features that require complex professional knowledge to assess, it seems reasonable that professional and nonprofessional 
evaluators will evaluate the pitches in similar ways, i.e., find certain levels of figurative language and gesturing similarly persuasive or unpersuasive. Replicating our findings with a sample of nonprofessional evaluators would thus increase confidence in the generalizability of the findings. Student participants received $£ 5(\$ 7.21)$ for taking part. The average age was $20.07(\mathrm{SD}=2.87)$ and $58 \%$ were female.

We invited participants in both samples to watch a video of an entrepreneur pitching an idea for a new business by following a hyperlink to an online study website. After completing equipment tests to ensure that the video presentations would be suitably visible and audible, participants were instructed to imagine they were considering investing in a new venture and were about to view the entrepreneur's funding pitch. After watching the presentation, participants completed various measures using an inbuilt survey tool.

\section{Materials and Manipulations}

Materials. We manipulated the degree of figurative language and gesturing used by the entrepreneur by creating four videos corresponding to the treatment groups. As Brooks et al. (2014) note, video pitches are an increasingly common way for entrepreneurs to communicate with potential investors. Investment websites such as Kickstarter and Crowdcube enable different types of investors to volunteer finance based on entrepreneurs' video pitches, while platforms such as AngelList enable accredited investors to provide equity to new businesses based on uploaded video pitches. To create our video pitches, we employed a professional actor and cameraman and video-recorded the actor performing four different versions of the same pitch. The videos were consistent with the four contrasting approaches to pitching identified among entrepreneurs in the field in Study 1. To ensure the presentations possessed psychological realism (Colquitt, 2008), we based the script for the pitch on a real-life case and changed the identifying details. This case involved an individual entrepreneur who had developed a digital 
temperature-controlled compression device for treating sports and physical injuries. We selected this case as the product and the associated technology, whilst novel and unfamiliar to investors, does not require advanced knowledge to assess its investment potential.

The first experimental factor we manipulated was the use of figurative language by the entrepreneur to frame his new venture. In the low figurative language conditions, the entrepreneur delivered the pitch without figurative language, providing a literal and technical description of the venture focused on facts associated with the product and business. In the high figurative language conditions, the pitch included the same basic information on the nature of the product and the market but also a range of figurative expressions. These expressions included the use of an anecdotal story to link the product's origins to the entrepreneur's own embodied experience of treating an injury that was sustained while playing soccer. He also likened his venture (i.e. shifting from ice packs to an electronic treatment device) to the progression from analogue to digital communication technologies to connote a 'next generation' technology. Furthermore, when stating the market penetration strategy for the product, he described this through a range of metaphorical expressions as a "targeted" and controlled "top-down" movement into a series of markets and "towards growth", whereby he not only "penetrates" each market but is also able through this strategy to "cover" each of these markets in its entirety. Hence, the contrast between the low and high figurative language conditions replicated the natural conditions observed in Study 1, where we observed a contrast between the absence of figurative language and the targeted use of metaphors and analogies and personal anecdotes to frame the core venture and its product or service.

The second experimental factor we manipulated was the use of gestures. In the low gesture conditions, the entrepreneur used no explicit hand or overt bodily gestures in his presentation. The actor's hands and body remained static during the presentation with his hands 
clasped in front of the body, in a manner consistent with some entrepreneurs observed in Study 1. In the high gesture conditions, the actor delivered the pitch using frequent beat gestures and a series of ideational gestures. Beat gestures included a rhythmic beating of the arms and hands to emphasize the pattern and cadence of the speech and single beats to mark important points in the pitch. The ideational gestures used included iconic gestures (e.g., simulating the product compressing the entrepreneur's knee joint) and metaphoric gestures (e.g., moving the arms and hands away from the body in a forward motion to represent the growing market for the product). These ideational gestures communicated and embodied physical and abstract meanings. Hence, the high gesture condition mimicked the natural conditions observed in Study 1, in which entrepreneurs frequently combined different types of gestures in their pitch. Figure 1 illustrates examples of the gestures used in the pitches.

\section{INSERT FIGURE 1 AROUND HERE}

Notwithstanding our manipulations of language use and gesture, the pitches adhered to a strict script to ensure that in each condition the basic content of the pitch was identical. Specifically, each presentation contained information typically included in a pitch to potential investors, including detail on the product's features (its evolution, development, technological competencies and medical benefits), the characteristics of the target market (industry size, market growth), development of the business and strategy (sales to date, marketing and distribution), and details on the management team. The experimental design enabled us to control for possible variations in pitching arising from the venture idea itself, the characteristics of the individual entrepreneur (e.g., age, gender, etc.) and other nonverbal parameters (e.g., physical appearance, posture, visual gaze, etc.), which were all held constant.

Manipulation Checks. We checked the efficacy of our manipulations by collecting responses to our materials from 128 working adults recruited via Amazon Mechanical Turk 
(Buhrmester, Kwang \& Gosling, 2011). We paid participants one dollar for taking part. Sixty one per cent were male, the average age was $35.44(\mathrm{SD}=10.29)$, and participants had an average of 14.13 years $(\mathrm{SD}=11.50)$ full-time work experience. We randomly assigned participants to watch one of the four videos and to rate the language and gesturing perceived; we also included an instructional manipulation check and factual questions on the video content to detect inattention and satisficing response behavior (Paolacci, Chandler \& Ipeirotis, 2010).

We measured perceptions of the nature and extent of figurative language using the mean of three items (the presenter "used a personal story to explain the origins of the product and/or business", "used metaphors and analogies to describe the product and/or business", and "used descriptive and imaginative language to explain the product and/or business") measured on an 11 -point scale $(0=$ "Not at All" to $10=$ "A Lot"; $\alpha=.72, \mathrm{M}=7.06, \mathrm{SD}=2.56)$. We measured perceptions of the nature and extent of gesturing using the mean of three further items (the presenter "used hand gestures while speaking", "used simple hand gestures when describing the product and/or business, such as waving his hand in rhythm with speech and using his hands to emphasize points", and "used complex hand gestures while describing the product and/or business, such as using his hands to demonstrate their features", using the same scale $(\alpha=.87, \mathrm{M}$ $=5.39, \mathrm{SD}=3.12$ ). Participants who viewed the pitches with frequent use of figurative language $(\mathrm{M}=8.79, \mathrm{SD}=1.58)$ perceived significantly higher levels of figurative language than those who viewed the versions where such language was absent $(\mathrm{M}=5.27, \mathrm{SD}=2.10 ; t(126)=10.71$, $p<.001)$. Participants who viewed the high gesture pitches $(\mathrm{M}=7.68, \mathrm{SD}=1.96)$ perceived significantly higher levels of gesturing than those who viewed the low gesture pitches $(\mathrm{M}=2.87$, $\mathrm{SD}=2.26 ; t(126)=12.93, p<.001)$. These results confirm the efficacy of our manipulations. 


\section{Measures}

Dependent variable: Propensity to invest. Some previous studies have measured potential investors' decision to invest in the business depicted in entrepreneurs' pitches using a single binary choice outcome (e.g., "would you invest?", “yes” or “no”; see Chen et al., 2009). However, our research led us to question the validity and diagnosticity of this type of measure. Based on pre-tests of our survey instrument with twelve experienced investors, we found that investors deemed it unrealistic to make a yes/no investment decision based solely on a pitch. Rather, they characterized the investment decision as a staged process involving multiple steps before such a decision was taken. From this perspective, the communicative act of the pitch (including its language and gestures), is crucial for securing progress in this process - if not necessarily sufficient to secure a yes/no investment decision. According to this view, after seeing pitches investors decide whether or not to pursue the opportunity further, involving finding out more about the business/market and the entrepreneur, to inform their decision to invest. This stage-based view is consistent with models of investor decision-making that distinguish a firstphase and second-phase evaluation (e.g., Fried \& Hisrich, 1994), the former involving a first-line check on the feasibility of the entrepreneur and business and the latter involving probes into financial and other aspects of the venture.

Building on this stage-based view, we used four items to measure investment intentions. Respondents indicated whether, based on the pitch, they would take the opportunity further with a view to investing in the business, by "finding out more information about the business", "doing further research into the industry and/or market of the business", "meeting with the entrepreneur again", and "finding out more information about the entrepreneur/management team", using a Likert-type scale ( $1=$ 'Strongly Disagree' to $5=$ 'Strongly Agree'). We averaged responses to these items to form a single score of investment intentions (sample $1 \alpha=.94$, sample $2 \alpha=.82$ ). 
A further limitation of a binary yes/no outcome for measuring investors' propensity to invest is that it is potentially too coarse (Aguinis, Pierce \& Culpepper, 2008) to distinguish persuasive pitches from unpersuasive ones. In our pre-testing several investors said that they would never invest without undertaking their own research into the background of the entrepreneur; under such conditions, even a pitch that was very persuasive would be insufficient to obtain a yes decision. Based on these observations, we employed a more nuanced indicator by asking participants to indicate how likely they would be to invest in the business, using an 11point scale anchored at $0=$ ' $0 \%$ zero chance' and $10=$ ' $100 \%$ certain' (Huang \& Pearce, 2015).

Previous research suggests that when evaluating new ventures potential investors combine the different dimensions of their evaluations of the entrepreneur and his/her business and factor them into an overall judgment of an opportunity's investment potential (Brooks et al., 2014; Huang \& Pearce, 2015). Supporting this view, our four-item intentions measure and single-item likelihood measure were significantly correlated (sample $1 r=.66, p<.001$; sample $2, r=.68, p<.001)$ and combining the five items yielded a reliable single scale (sample $1 \alpha=$ .90 , sample $2 \alpha=.73$ ). To examine whether the two measures were tapping into a common underlying construct, we first conducted a principle components analysis on sample 1 . The results supported this view; all five items loaded significantly on a single component (all loadings $>.76$ ), which had an eigenvalue of 3.93 and explained $78.56 \%$ of the variance. To confirm this structure we conducted a confirmatory factor analysis on sample 2 . The results showed that a single factor model fit the data well: $\chi^{2}=5.70[3], p=1.27$, comparative fit index $(\mathrm{CFI})=.99$, root mean squared error of approximation $(\mathrm{RMSEA})=.07$. In comparison, a two factor model with the intentions items loading on one factor and investment likelihood as a second factor fit the data poorly: $\chi^{2}=62.65[6], p<.000, \mathrm{CFI}=.82, \mathrm{RMSEA}=.23$. Accordingly, 
we first standardized the measures of investment intentions and investment likelihood and then combined them into a single summative indicator, which we term propensity to invest.

Mental imagery. We used an established scale to measure the nature and extent of the mental imagery triggered by the pitches. This variable is distinct from entrepreneurial passion (Chen et al., 2009), which assumes that bodily displays on the part of the entrepreneur express affect (i.e. passion) rather than meaning. In contrast, our measure of mental imagery focuses on imagination and feeling on the part of the viewer, consistent with our theorizing that mental imagery is a key mechanism by which investors understand new products and ventures, as triggered in the present case by an entrepreneur's verbal and non-verbal communication acts. To assess the mental imagery evoked in pitches, we used a measure of communication-evoked imagery originally developed by Bone and Ellen (1992) and subsequently refined by Babin and Burns (1998). Since we were primarily interested in the effects of figurative language and gesture on viewers' ability to mentally simulate the product and business, we focused on two dimensions of evoked imagery most closely related to simulated action, namely imagery quantity and imagery elaboration (Escalas, 2004). Three items assessed the quantity of imagery experienced (e.g. "many images came to mind") on a seven-point Likert style scale (1=Strongly Disagree to 7=Strongly Agree). Three items assessed imagery elaboration, which concerns viewers' bodily responses evoked by the imagery experienced (e.g. "I imagined what it was like to use the product", "I imagined the feel of the product"), using the same scale. We summed responses to these six items to form our measure of mental imagery, which showed good reliability (sample $1 \alpha=.86$, sample $2 \alpha=.88$ ).

Passion and preparedness. As well as seeking to confirm the hypothesized mediating effect of mental imagery, we also sought to conduct a comparative test of gesture's indirect effects through mental imagery against other possible mediators established in the literature, 
namely passion and preparedness. To this end, we used the 11-item scale developed by Chen et al. (2009) to measure perceptions of the passion and preparedness shown by the entrepreneur. The scale breaks down into two dimensions. The first corresponds to the preparedness of the presenter (which Chen and colleagues termed 'cognitive passion') and includes 5 items, including "the presentation content had substance" and "the presentation was thoughtful and indepth". The second dimension concerns the passion displayed by the presenter, termed 'affective passion' by Chen and colleagues, and uses 6 items concerning their body language (e.g. "the presenter had energetic body movements") and verbal delivery (e.g. "the presenter talked with varied tone and pitch"). All items were measured on a 5-point scale ( $1=$ Not at All to 5= Very Much). Both subscales demonstrated good reliability (passion: sample $1 \alpha=.92$, sample $2 \alpha=$ .92 ; preparedness: sample $1 \alpha=.87$, sample $2 \alpha=.88$ ).

Control variables. We measured four individual characteristics that could theoretically influence participants' evaluations in order to control for these variables in our analyses. First, because research suggests that investors become more risk seeking with age (Summers, Duxbury, Hudson \& Keasey, 2006), we recorded respondents' age. Second, since research suggests than men are more overconfident in their investments than women (Barber \& Odean, 2001), we also recorded respondents' gender. For sample 1 we recorded two additional controls. We recorded investors' experience investing in new ventures (in years) because prior research shows that experienced investors may make decisions differently from inexperienced investors; for example by using rules of thumb based on knowledge learned (Korniotis \& Kumar, 2011). Also, there is evidence that different types of investors have different attitudes and preferences and may evaluate ventures differently; for instance, angel investors give greater emphasis to the entrepreneur while venture capitalists emphasize market and financial issues (Mason \& Stark, 
2004). For this reason, we also dummy variable coded investor type (personal/angel/peer investors $=0$, venture capitalists and organizational investors $=1$ ) as a further control variable.

Following recent guidelines for the use of statistical control variables (Becker, 2005; Spector \& Brannick, 2011), we initially ran our analyses including the appropriate controls and then re-ran them without controls. For sample 1 analyses, we initially included all four variables as controls. For sample 2 analyses, we initially included gender and age. However, none of the controls was significantly correlated with the dependent variable. Moreover, the pattern of results was the same with and without the controls (i.e., all hypotheses test results were identical and all substantive variable relations were equivalent), meaning that we can rule out the controls as a potential explanation for the findings. Because including impotent and/or suppressing control variables can reduce statistical power and increase the chances of Type I and Type II errors (Becker, 2005), below we report only the results from the analyses without controls.

\section{Data Analysis}

We conducted confirmatory factor analyses to examine the factor structure of the four focal variables: mental imagery, passion, preparedness, and propensity to invest. The expected four-factor solution demonstrated good fit (sample $1: \chi^{2}[199]=322.46$, CFI $=.94$, RMSEA $=$ .07 ; sample $\left.2: \chi^{2}[198]=345.19, \mathrm{CFI}=.93, \mathrm{RMSEA}=.06\right)$ and for both samples was a significantly better fit than alternative models, including a three-factor model with passion and preparedness loading on one factor and mental imagery and propensity to invest loading on two other factors, a two factor model with all items relating to the pitch loading on one factor and investment items loading on the other, and a single factor model.

\section{Results and Discussion}

Table 2 shows means, standard deviations and correlations for both samples. Table 3 shows group means. 
Effects of figurative language and gesture on propensity to invest. We used a two-way analysis of variance to test hypotheses 1 to 3 concerning respectively the main effect of figurative language, the main effect of gesturing, and their interaction effect on the propensity to invest. There was no main effect of figurative language in either sample (sample 1: $F[1,120]=$ $.08, p=.76$; sample $2: F[1,176]=3.08, p=.08)$. Hence, hypothesis 1 is not supported.

However, the main effect of gesture was significant in both samples (sample $1: F[1,120]=6.28$, $p=.01, \eta^{2}=.05$; sample $\left.2: F[1,176]=7.15, p=.008, \eta^{2}=.04\right)$. When the entrepreneur used a high level of gesturing (sample 1: $M=.22, S E=.12$; sample $2: M=.17, S E=.09$ ), participants showed a greater propensity to invest than when the entrepreneur used a low level of gesturing (sample 1: $\mathrm{M}=-.19, S E=.11$; sample $2: M=-.17, S E=.09$ ). These findings support hypothesis 2. However, the interaction between figurative language and gesture was not significant (sample 1: $F[1,120]=.02, p=.89$; sample $2: F[1,176]=.53, p=.47)$. Thus, hypothesis 3 is not supported.

\section{INSERT TABLES 2 AND 3 AROUND HERE}

The mediating influence of mental imagery. Hypothesis 4 predicted that mental imagery mediates the effects of gesture on the propensity to invest. However, we recognized that gesture might influence the propensity to invest through multiple routes. That is, gesture might simultaneously influence the propensity to invest through mental imagery, passion and preparedness. Accordingly, we tested hypothesis 4 using models of mediation involving multiple mediators (Hayes, 2013; Preacher and Hayes, 2008), theorizing mental imagery, passion, and preparedness as parallel mediators. To test for mediation, we used the PROCESS procedure developed by Hayes (2013). This procedure involved using bootstrapping to draw 5,000 replacement samples from the focal sample and constructing bias-correcting confidence intervals around the indirect effects. Confidence intervals that do not contain zero indicate a significant 
indirect effect. However, after initially examining the relationships between the independent variable, proposed mediators, and the dependent variable, we observed that gesture was not significantly related to preparedness (Sample 1: $B=.14, S E=.16, t=.85, p=.40$; Sample 2: $B=$ $.13, S E=.11, t=1.25, p=.21)$. Hence, we dropped preparedness from this analysis and included only passion and mental imagery as mediators.

Table 4 shows the results for the full regression model predicting propensity to invest. Table 5 shows the results of the bootstrapped tests for the indirect effects. The indirect effect of gesture through mental imagery was significant in both samples (Sample 1: $b=.20, S E=.09$, $95 \%$ CI $[.04, .39]) ;$ Sample $2: b=.10, S E=.06,95 \%$ CI $[.01, .24])$. These results support Hypothesis 4; mental imagery mediates the effects of gesture on the propensity to invest. In contrast, the indirect effect of gesture via passion was not significant for sample $1(b=.14, S E=$ $.12,95 \% \mathrm{CI}[-.09, .39])$ but was significant for sample $2(b=.14, \mathrm{SE}=.06,95 \% \mathrm{CI}[.04, .27])$. Furthermore, for sample 2 the indirect effect via mental imagery was not significantly different from the indirect effect via passion (contrast coefficient $=.04, S E=.08,95 \% \mathrm{CI}[-.13, .18]$ ). These results suggest that for professional investors mental imagery rather than passion mediates the effects of gesture on the propensity to invest, while for non-professional evaluators mental imagery and passion collectively mediate the effects of gesture.

\section{INSERT TABLES 4 - 6 AND FIGURE 2 AROUND HERE}

Post hoc analysis: Moderated mediation. To tease out the conditions under which the theorized mediators may be more or less dominant, in post hoc analysis we examined the possibility that the indirect effects of gesture might depend on the level of figurative language used. This possibility is consistent with the idea that figurative speech provides a basis for accompanying ideational gestures to convey symbolic meanings more strongly (Alibaba et al., 1999; Congdon et al., 2018), so that when gesturing is allied to figurative speech it is better 
equipped to evoke mental imagery, strengthening this pathway through which gesturing influences the propensity to invest. In contrast, it seems likely that gesture can communicate passion even without the accompanying use of figurative language; in this case, the indirect effect of gesturing through passion should not depend on the level of figurative language.

To test these ideas, we used Hayes's (2013) procedure to perform a conditional process analysis, drawing 5,000 replacement samples to calculate bootstrapped confidence intervals for the conditional indirect effects. As Table 6 shows, the results confirmed the presence of moderated mediation. When a pitch involved a low level of figurative language, the indirect effect of gesture on the propensity to invest through mental imagery was not significant (sample $1: b=.11, S E=.08,95 \%$ CI $[.00, .31]$; sample $2: b=.04, S E=.04,95 \%$ CI $[-.01, .17])$. However, when a pitch involved a high level of figurative language, the indirect effect of gesture on the propensity to invest through mental imagery was significant (sample $1: b=.28, S E=.11$, $95 \%$ CI $[.08, .52]$; sample $2: b=.14, S E=.08,95 \%$ CI $[.01, .32])$. Moreover, the index of moderated mediation (Hayes, 2015) confirmed that the indirect effect of gesturing through mental imagery was significantly different at high and low levels of figurative language (sample 1: .17, SE $=.09,95 \%$ CI $[.04, .45]$; sample $2: .10, \mathrm{SE}=.07,95 \% \mathrm{CI}[.01, .30)$. In contrast, the index of moderated mediation for passion was not significant (sample 1: $-.29, S E=.23,95 \% \mathrm{CI}$ $[-.78, .12]$; sample 2: $.08, S E=.10,95 \% \mathrm{CI}[-.12, .28])$. These results show that the indirect effect of gesture through mental imagery depended on the level of figurative language whereas the indirect effect through passion did not. Figure 2 shows this moderated mediation model. The results of Study 2 extend the findings of Study 1 by confirming that the types of language and gesturing we observed entrepreneurs using in their pitches in the field do influence how others evaluate the investment potential of their ventures. In particular, high levels of gesturing - specifically the use of beat and ideational gestures - had significant effects on the 
propensity to invest, a finding we replicated across two samples. Indeed, when we analyzed the specific effects of gesturing on investment likelihood we found that among investors the likelihood of investing was $12.06 \%$ higher for pitches with a high level of gesturing compared to those with a low level of gesturing (95\% CI mean difference $[3.63 \%, 18.29 \%])$. The results also support our thesis that the mental imagery evoked by gestures mediates their effects on the propensity to invest. We thus introduce a new mechanism to explain how entrepreneurs' nonverbal expressive behaviors can influence judgments of a venture's investment potential. However, the findings also show that this mechanism depends on how an entrepreneur frames his/her venture, suggesting that only when gestures are coupled with figurative language are entrepreneurs able to trigger the type of mental imagery that persuades potential investors of the venture's worth.

\section{GENERAL DISCUSSION}

Based on an inductive theory-building study and a controlled experiment with two samples, our findings extend current understanding of how entrepreneurs impact investment judgments through their language and gesturing in a pitch. Our findings revealed considerable natural variation in how entrepreneurs pitch. Study 1 identified four distinct pitching strategies that are structured around the same topics (i.e., the product and market, team and organization, and financial projections), but differ significantly in whether literal or figurative language is used and whether the pitch is delivered with a frequent and varied use of gestures, or not.

In a controlled experiment we subsequently explored the effectiveness of these different strategies, systematically testing the extent to which investors are swayed by the entrepreneur's figurative language, his/her gesturing, or indeed by a combination of the two. We found empirical support for the effectiveness of pitching strategies where entrepreneurs not only gesture on a frequent basis but also use specific ideational gestures to symbolically depict their 
product or service and venture. The effect of figurative language, as a way of framing a venture and its products or services, proved to have a limited direct effect across two samples. Our results also highlight a key mechanism through which gesturing influences investors, namely by evoking mental imagery of the venture and its product in the minds of investors. Specifically, we find that demonstrating and depicting a business idea with gestures increases the propensity to invest by triggering mental imagery, with this indirect effect being particularly strong when gestures are coupled with figurative language. Through such mental imagery, gestures present perceptual and imagistic representations of products and venture ideas, which investors can comprehend in an immediate and intuitive manner (McNeill, 1992). This result intriguingly suggests that information that is conveyed in a pitch through gestures may have a higher impact than information given only verbally (Beattie, 2003).

Thus, we find that instead of being swayed by figurative language directly, potential investors appear to be looking for a concrete articulation and gestural depiction of the entrepreneur's basic ideas. The uncertain and interpersonal nature of the pitch may in fact augment the role of gestures over language. Under such uncertain conditions, investors may shift to an intuitive mode of processing and focus on bodily cues and any other information that they can glean from the person's presence and performance to anchor their judgments and strengthen their beliefs about the investment potential (Huang \& Pearce, 2015; Mitteness et al., 2012).

\section{Theoretical and Research Implications}

The first implication of our findings is for research on entrepreneurial rhetoric and framing (Lounsbury \& Glynn, 2001). Notwithstanding the possibility that future research might uncover other forms of rhetoric and storytelling in pitches that does more directly persuade investors, our findings suggest that the role and effect of such strategic forms of language use may have been overemphasized. A contextualized and more empirically driven approach is 
therefore needed in future research to provide a more detailed understanding of the function and effectiveness of different forms of language use across various entrepreneurial tasks and communicative interactions. Prior entrepreneurship research has often started at the outset with the theoretical assumption that specific forms of linguistic framing matter and that these are, when effectively used, able to drive the perceptions and evaluations of others (e.g., Cornelissen \& Clarke, 2010; Navis \& Glynn, 2011). Depending on the context, this may not necessarily be the case. This base assumption also privileges the communicative acts of the entrepreneur, as the speaker, over those of the listener, whether they be investors or other resource providers (see, for example, Van Werven et al., 2015). A more symmetrical approach that models communication as a joint activity between entrepreneurs and investors would serve future research well. Such an approach implies the need to better connect the entrepreneurship and investment decisionmaking literatures (Huang \& Pearce, 2015), as we have attempted to do in our studies.

The second main implication of our research is for the emerging stream of work on expressive behaviors and investor judgments and decision-making (Huang \& Pearce, 2015). We highlight an entrepreneur's gesturing as a crucial form of non-verbal expressive behavior that influences investors in their evaluations of a business opportunity. Prior research has focused on frequent gesturing as an indicator of an entrepreneur's passion whilst pitching (Cardon et al., 2009; Chen et al., 2009; Murnieks et al., 2014). In our experimental study, we indeed found that gesturing makes entrepreneurs seem more passionate in the eyes of potential investors. Crucially, however, our findings also indicate that gesture is not only a carrier of emotion; rather, it plays a more central role in expressing meaning to persuade investors.

Our results suggest the need for further study of the role that expressive behaviors, including gestures, play in a pitch alongside the preparedness that an entrepreneur demonstrates on stage and in her or his written business plans (cf. Huang \& Pearce, 2015). In addition, as prior 
research has produced equivocal findings concerning the influence of entrepreneurs' gesturing and their demonstration of affective passion (Chen et al., 2009; Mitteness et al., 2012; Murnieks et al., 2016), future research would benefit not only from recognizing gesturing as a significant form of non-verbal expressive behavior (Ambady \& Rosenthal, 1992) but also from distinguishing more clearly between the different types of gestures - such as beats and ideational gestures - we distinguished in order to better understand their functions and effects. Such distinctions may lead to more refined measures of the communicative functions of gestures, as opposed to compounding such functions into a simple frequency measure of gesturing as a proxy for conveying emotions or passion (Chen et al., 2009; cf. Ekman \& Friesen, 1969).

Although in this research we focused on gesture as a route to persuasion via mental imagery, it seems likely that from the perspective of verbal and non-verbal expressive behaviors (Ambady \& Rosenthal, 1992; Bonacci et al., 2016) additional non-verbal modalities - including paralinguistic elements (such as intonation, pitch, and prosody), body posture and facial expressions - may shape entrepreneurs' interactions with investors. These other modalities have so far not been studied although they may also turn out to be important drivers of, for example, investors' intuitions about entrepreneurs (Huang \& Pearce, 2015) or of the relationship that the entrepreneur and investor build up over time (Huang \& Knight, 2017). It may also be interesting to compare the role of inter-personal forms of communication, such as pitching, where these bodily modalities play a role, with mediated forms of communication, such as IPO prospectuses (Martens et al., 2007) or business plans, in order to identify the effects of different forms of entrepreneurial communication on investor decision-making.

Future research might also address some of the limitations of our research. In our experimental materials, we used a male actor to play the role of the entrepreneur. Given that the gender of the entrepreneur seems to influence investors' evaluations (Brooks et al., 2014), an 
interesting question is whether the effects we found also hold for female entrepreneurs. We furthermore manipulated the use of both repetitive hand gestures (beats) and gestures that symbolize or convey ideas (ideational gestures) in a conjoint manner as part of the treatment materials for the experiment, mimicking the natural conditions that we observed in study 1 . Future research however may control for the effect of beats alongside ideational gestures on investors' evaluations, replicating and extending the current study. Another boundary condition of our experimental study is that we focused on a basic technological product that whilst uncertain in its future revenues would be possible to understand by experienced and novice investors alike. Whilst we believe that this increases the generalizability of our findings, future research may usefully examine whether the effects that we found equally hold for products and services that are technically or conceptually more sophisticated and rely to a greater or lesser extent on the know-how of an investor. In terms of other limitations, we measured our mediators and dependent variable contemporaneously, which may have inflated the relationships we observed. To address this concern, future research should measure mediators of entrepreneurial communication so that they are separated in time from investment judgments and decisions. In conclusion, we hope that our findings stimulate further research on the nature and effects of verbal and nonverbal expressives used by entrepreneurs. This endeavor promises to further advance our understanding of effective entrepreneurial communication and provide evidence-based recommendations for entrepreneurs and investors in practice. 


\section{REFERENCES}

Aguinis, H., Pierce, C. A., \& Culpepper, S. A. 2008. Scale coarseness as a methodological artifact: Correcting correlation coefficients attenuated from using coarse scales. Organizational Research Methods, 12: 623-652.

Alibali, M. W., Boncoddo, R. \& Hostetter, A. B. 2014. Gesture in reasoning: An embodied perspective. In L. Shapiro (Ed.) The Routledge handbook of embodied cognition: 150159. New York: Routledge.

Alibali, M. W., Heath, D. C. \& Myers, H. J. 2001. Effects of visibility between speaker and listener on gesture production: Some gestures are meant to be seen. Journal of Memory and Language, 44: 169-188.

Ambady, N. \& Rosenthal, R. 1992. Thin slices of expressive behavior as predictors of interpersonal consequences: A meta-analysis. Psychological Bulletin. 111:256-274

Babin, L. A \& Burns, A. C. 1998. A modified scale for the measurement of communicationevoked mental imagery. Psychology and Marketing, 15: 261-278.

Barber, B.M. \& Odean, T., 2001. Boys will be boys: Gender, overconfidence, and common stock investment. Quarterly Journal of Economics, 116: 261-292.

Barsalou, L. W. 1999. Perceptual symbol systems. Behavioral and Brain Sciences, 22: 577-660.

Bartel, C. A., \& Garud, R. 2009. The role of narratives in sustaining organizational innovation. Organization Science, 20: 107-17.

Beattie, G. 2003. Visible thought: The new psychology of body language. London: Routledge.

Becker, T.E., 2005. Potential problems in the statistical control of variables in organizational research: A qualitative analysis with recommendations. Organizational Research Methods, 8: 274-289.

Bettis, R.A., Helfat, C.E. and Shaver, J.M. 2016. The necessity, logic, and forms of replication. Strategic Management Journal, 37: 2193-2203.

Bird, B. \& Schjoedt, L. 2009. Entrepreneurial behavior: Its nature, scope, recent research, and agenda for future research. Understanding the Entrepreneurial Mind, 24: 327-358.

Bonaccio, S., O'Reilly, J., O'Sullivan, S., \& Chiocchio, F. 2016. Nonverbal behavior and communication in the workplace: A review and an agenda for research. Journal of Management, 42: 1044 - 1074.

Bone, P. F and Ellen, P. S 1992. The generation and consequences of communication-evoked imagery. Journal of Consumer Research, 19: 93-104.

Brooks, A.W., Huang, L., Kearney, S.W. and Murray, F.E., 2014. Investors prefer entrepreneurial ventures pitched by attractive men. Proceedings of the National Academy of Sciences, 111: 4427-4431.

Brush, C. G., Greene P. G. \& Hart, M. M. 2001. From initial idea to unique advantage: The entrepreneurial challenge of constructing a resource base. Academy of Management Executive, 15: 64-78.

Buhrmester, M., Kwang, T. and Gosling, S.D., 2011. Amazon's Mechanical Turk: A new source of inexpensive, yet high-quality, data? Perspectives on Psychological Science, 6: 3-5.

Cardon, M.S.; Sudek, R. and Mitteness, C. 2009. The impact of perceived entrepreneurial passion on angel investing. Frontiers of Entrepreneurship Research, 29, 2: Article 1.

Carletta, J. 1996. Assessing agreement on classification tasks: the kappa statistic. Computational Linguistics, 22, 249-54.

Cassar, G. 2004. The financing of business start-ups. Journal of Business Venturing, 19: 261284. 
Cienki. A. 2005. Image schemas and gesture. In B. Hampe (Ed.) Perception to meaning: Image schemas in cognitive linguistics: 421-442. Berlin: Mouton de Gruyter.

Chen, X. P., Yao, X. \& Kotha, S. 2009. Entrepreneur passion and preparedness in business plan presentations: A persuasion analysis of venture capitalists' funding decisions. Academy of Management Journal, 52: 199-214.

Chu, M. and Kita, S., 2011. The nature of gestures' beneficial role in spatial problem solving. Journal of Experimental Psychology: General, 140: 102-116.

Clark, A. 1996. Being there: Putting brain, body and world together. Cambridge MA: MIT.

Clarke, J. 2011. Revitalizing entrepreneurship: How visual symbols are used in entrepreneurial performances. Journal of Management Studies, 48: 1365-1391.

Colquitt, J. A. 2008. Publishing laboratory research in AMJ: A question of when, not if. Academy of Management Journal, 51: 616-620.

Congdon, E. L., Novack, M. A., \& Goldin-Meadow, S. 2018. Gesture in experimental studies: How videotape technology can advance psychological theory. Organizational Research Methods, 21: 489-499.

Cook, S. W. \& Tanenhaus, M. K. 2009. Embodied communication: Speakers' gestures affect listeners' actions. Cognition, 113: 98-104.

Corbin, J., \& Strauss, A. 2008. Basics of qualitative research: Techniques and procedures for developing grounded theory. Thousand Oaks: Sage Publications, third edition.

Cornelissen, J. \& Clarke, J. 2010. Imagining and rationalizing opportunities: Inductive reasoning, and the creation and justification of new ventures. Academy of Management Review, 35: 539-557.

Deignan, A. 2005. Metaphor and corpus linguistics. Amsterdam: John Benjamins.

Ekman, P. \& Friesen, W. V. 1969. The repertoire of non-verbal behavior. Categories, origins, usage and coding. Semiotica, 1: 49-98.

Elliott, W.B., Hodge, F.D., Kennedy, J.J. and Pronk, M. 2007. Are MBA students a good proxy for nonprofessional investors? The Accounting Review, 82(1), pp.139-168.

Escalas, J.E. 2004. Imagine yourself in the product: Mental simulation, narrative transportation, and persuasion. Journal of Advertising, 33: 37-48.

Fried, V.H. \& Hisrich, R.D., 1994. Toward a model of venture capital investment decision making. Financial Management, 23: 28-37.

Garud, R., Schildt, H. \& Lant, T. 2014. Entrepreneurial storytelling, future expectations, and the paradox of legitimacy. Organization Science, 25: 1479 - 1492.

Giorgi, S. \& Weber, K. 2015. Marks of Distinction: Framing and Audience Appreciation in the Context of Investment Advice. Administrative Science Quarterly, 60: 333-367.

Goldin-Meadow, S. 1999. The role of gesture in communication and thinking. Trends in Cognitive Science, 3: 419-429.

Goldin-Meadow, S. \& Beilock, S.L. 2010. Action's influence on thought: The case of gesture. Perspectives on Psychological Science, 5: 664-674.

Hayes A. F. 2013. Introduction to mediation, moderation, and conditional process analysis: $A$ regression-based approach. New York: Guilford Press.

Hayes, A. F. 2015. An index and test of linear moderated mediation. Multivariate Behavioral Research, 50: 1-22.

Hostetter, A.B. \& Alibali, M.W. 2008. Visible embodiment: Gestures as simulated action. Psychonomic Bulletin \& Review, 15: 495-514. 
Huang, L., \& Knight, A.P. 2017. Resources and relationships: An exchange theory of the development and effects of the entrepreneur- investor relationship, Academy of Management Review, 42: 80-102.

Huang, L. \& Pearce, J. 2015. Managing the Unknowable: The Effectiveness of Early-stage Investor Gut Feel in Entrepreneurial Investment Decisions, Administrative Science Quarterly, 4: 634-670.

Kelly, S. D., Özyürek, A., \& Maris, E. 2010. Two sides of the same coin: Speech and gesture mutually interact to enhance comprehension. Psychological Science, 21: 260-267.

Kendon, A. 2004. Gesture: Visible action as utterance. Cambridge: Cambridge University Press.

Korniotis, G.M. \& Kumar, A. 2011. Do older investors make better investment decisions? The Review of Economics and Statistics, 93: 244-265.

Lakoff, G., \& Johnson, M. 1980. Metaphors we live by. Chicago: University of Chicago Press.

Libby, R., Bloomfield, R. and Nelson, M.W., 2002. Experimental research in financial accounting. Accounting, Organizations and Society, 27: 775-810.

Locke, K. 2001. Grounded theory in management research. London: Sage Publications.

Lounsbury, M. \& Glynn, M. A. 2001. Cultural entrepreneurship: Stories, legitimacy, and the acquisition of resources. Strategic Management Journal, 22: 545-564.

Martens, M.L., Jennings, J.E., \& Jennings, P.D. 2007. Do the stories they tell get them the money they need? The role of entrepreneurial narratives in resource acquisition. Academy of Management Journal, 50: 1107-1132.

Mason, C. and Stark, M., 2004. What do investors look for in a business plan? A comparison of the investment criteria of bankers, venture capitalists and business angels. International Small Business Journal, 22: 227-248.

Maxwell, A. L., Jeffrey, S.A. \& Lévesque, M. 2011. Business angel early stage decision making. Journal of Business Venturing, 26: 212-225.

McNeill, D. 1992. Hand and mind: What gestures reveal about thought. Chicago: University of Chicago Press.

McNeill, D. 2005. Gesture and thought. Chicago: University of Chicago Press.

Mitteness, C., Sudek, R. \& Cardon, M.S. 2012. Angel investor characteristics that determine whether perceived passion leads to higher evaluations of funding potential. Journal of Business Venturing 27: 592-606.

Moon, R.E. 1998. Fixed expressions and idioms in English: A corpus-based approach. Oxford: Clarendon Press.

Murnieks, C.Y, Mosakowski, E., \& Cardon, M.S. 2014. Pathways of passion: Identity centrality, passion, and behavior among entrepreneurs. Journal of Management, 40: 1583-1606.

Murnieks, C.Y, Cardon, M.S., Sudek, R., White, T.D., \& Brooks, W.D. 2016. Drawn to the fire: The role of passion, tenacity and inspirational leadership in angel investing. Journal of Business Venturing, 31: 468-484.

Navis, C. \& Glynn, M.A. 2011. Legitimate distinctiveness and the entrepreneurial identity: Influence on investor judgments of new venture plausibility. Academy of Management Review, 36(3), 479-499.

Özyürek, A. 2014. Hearing and seeing meaning in speech and gesture: insights from brain and behavior. Philosophical Transactions of the Royal Society B, 369: 20130296.

Paolacci, G., Chandler, J. and Ipeirotis, P.G., 2010. Running experiments on Amazon Mechanical Turk. Judgment and Decision Making, 5: 411-419. 
Pollack, J. M., Rutherford, M. W. \& Nagy, B. G. 2012. Preparedness and cognitive legitimacy as antecedents of new venture funding in televised business pitches. Entrepreneurship Theory and Practice, 36: 915-939.

Pragglejaz Group 2007. MIP: A method for identifying metaphorically-used words in discourse. Metaphor and Symbol, 22: 1-39.

Preacher, K. J., \& Hayes, A. F. 2008. Asymptotic and resampling strategies for assessing and comparing indirect effects in multiple mediator models. Behavior Research Methods, 40: 879-891.

Shadish, W. R., Cook, T. D., \& Campbell, D. T. 2002. Experimental and quasi-experimental designs for generalized causal inference. Boston, MA: Houghton Mifflin.

Spector, P.E. and Brannick, M.T., 2011. Methodological urban legends: The misuse of statistical control variables. Organizational Research Methods, 14: 287-305.

Summers, B., Duxbury, D., Hudson, R. \& Keasey, K. 2006. As time goes by: An investigation of how asset allocation varies with investor age. Economics Letters, 91: 210-214.

Tsang, E.W. and Kwan, K.M., 1999. Replication and theory development in organizational science: A critical realist perspective. Academy of Management Review, 24: 759-780.

Van Werven, R., Bouwmeester, O., \& Cornelissen, J.P. 2015. The power of arguments: How entrepreneurs convince stakeholders of the legitimate distinctiveness of their ventures. Journal of Business Venturing 30: 616-631.

Vough, H. C., Bataille, C. D., Noh, S. C. \& Lee, M. D. 2015. Going off script: How managers make sense of the ending of their careers. Journal of Management Studies, 52: 414-440.

Weber, K., Heinze, K., \& DeSoucey, M. 2008. Forage for thought: Mobilizing codes in the movement for grass-fed meat and dairy products. Administrative Science Quarterly, 53, 529-567.

Wry, T., Lounsbury, M. \& Glynn M.A. 2011 Legitimating Nascent Collective Identities: Coordinating Cultural Entrepreneurship. Organization Science, 22: 449 - 463.

Wu, Y. C. \& Coulson, S. 2011. Are depictive gestures like pictures? Commonalities and differences in semantic processing. Brain and Language, 119: 184-195.

Zott, C. \& Huy, Q.N. 2007. How entrepreneurs use symbolic management to acquire resources. Administrative Science Quarterly, 52: 70-105. 
TABLE 1 Study 1: Results of Gesture and Language Coding Type and Frequency of Gestures

Type and Frequency of Figurative Language

\begin{tabular}{|c|c|c|c|c|c|c|c|c|c|}
\hline ase & $\stackrel{\widetilde{\varpi}}{\oplus}$ & 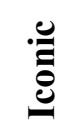 & : & 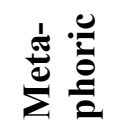 & $\begin{array}{c}\text { Total } \\
\text { Gestures/ } \\
\text { Minutes }\end{array}$ & Description of Gesturing & $\begin{array}{c}\text { Figurative } \\
\text { / Total } \\
\text { Words }\end{array}$ & $\begin{array}{l}\text { Proportion } \\
\text { Figurative }{ }^{b}\end{array}$ & Description of Framing \\
\hline
\end{tabular}

\section{Approach 1: The Literal Approach (Low use of gesture, Low use of figurative language)}

\begin{tabular}{|c|c|c|c|c|c|c|c|c|c|}
\hline $\begin{array}{l}\text { Cloud } \\
\text { Accounts }\end{array}$ & 0 & 1 & 0 & 0 & $\begin{array}{l}1 / 15.3 \\
(0.06)\end{array}$ & $\begin{array}{l}\text { Hands in trouser pockets for the } \\
\text { majority of the pitch. }\end{array}$ & $21 / 1504$ & 13.96 & $\begin{array}{l}\text { Common business idioms (e.g., } \\
\text { "entering the marketplace", } \\
\text { "follow our lead") }\end{array}$ \\
\hline $\begin{array}{l}\text { Screen for } \\
\text { Health }\end{array}$ & 1 & 0 & 1 & 0 & $\begin{array}{l}2 / 10.3 \\
(0.19)\end{array}$ & $\begin{array}{l}\text { Hands rest on podium for } \\
\text { majority of pitch; speaker reads } \\
\text { from script rarely looking up. }\end{array}$ & $11 / 1421$ & 7.74 & $\begin{array}{l}\text { Common business idioms (e.g., } \\
\text { "route to market") }\end{array}$ \\
\hline Meet Pal & 1 & 0 & 1 & 0 & $\begin{array}{l}2 / 12.4 \\
(0.16)\end{array}$ & $\begin{array}{l}\text { Hands are positioned behind the } \\
\text { speaker's back for the majority of } \\
\text { the pitch. }\end{array}$ & $16 / 2374$ & 6.74 & $\begin{array}{l}\text { Common business idioms (e.g., } \\
\text { "route to market") }\end{array}$ \\
\hline $\begin{array}{l}\text { Planet } \\
\text { Net }\end{array}$ & 0 & 0 & 1 & 1 & $\begin{array}{l}2 / 8.6 \\
(0.23)\end{array}$ & $\begin{array}{l}\text { Hands are placed on the podium } \\
\text { for the majority of the pitch. }\end{array}$ & $21 / 1544$ & 13.60 & $\begin{array}{l}\text { Common business idioms (e.g., } \\
\text { "there is a particular gap in the } \\
\text { market here") }\end{array}$ \\
\hline $\begin{array}{l}\text { Scent } \\
\text { Advance }\end{array}$ & 5 & 2 & 4 & 0 & $\begin{array}{c}11 / 14.4 \\
(0.76)\end{array}$ & $\begin{array}{l}\text { Hands placed on podium or in } \\
\text { trouser pockets through the pitch. }\end{array}$ & $21 / 1491$ & 14.08 & $\begin{array}{l}\text { Common business idioms (e.g., } \\
\text { "route to market") }\end{array}$ \\
\hline $\begin{array}{l}\text { Safe } \\
\text { Biotech }\end{array}$ & 10 & 2 & 5 & 3 & $\begin{array}{l}20 / 12.3 \\
(1.6)\end{array}$ & $\begin{array}{l}\text { Hands resting on podium or } \\
\text { behind speaker's back for much } \\
\text { of the pitch. }\end{array}$ & $20 / 1832$ & 10.92 & $\begin{array}{l}\text { Common business idioms (e.g., } \\
\text { "route to market") }\end{array}$ \\
\hline
\end{tabular}

Approach 2: The Rhetorical Approach (Low use of gesture, High use of figurative language)

$\begin{array}{llllll}\begin{array}{l}\text { In Vitro } \\ \text { Testing }\end{array} & 2 & 5 & 3 & \begin{array}{c}14 / 10.45 \\ (1.3)\end{array} & \begin{array}{l}\text { Left hand rests in pocket for } \\ \text { much of the pitch while the right } \\ \text { hand rests on the podium. }\end{array}\end{array}$


TABLE 1 Study 1: Results of Gesture and Language Coding Type and Frequency of Gestures

Type and Frequency of Figurative Language

\begin{tabular}{|c|c|c|c|c|c|c|c|c|c|}
\hline Case & 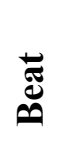 & 苛 & 苋 & $\sum_{\Sigma}^{\frac{d}{d}} \frac{e}{2}$ & $\begin{array}{c}\text { Total } \\
\text { Gestures/ } \\
\text { Minutes }^{\text {a }}\end{array}$ & Description of Gesturing & $\begin{array}{c}\text { Figurative } \\
\text { / Total } \\
\text { Words }\end{array}$ & $\begin{array}{l}\text { Proportion } \\
\text { Figurative }{ }^{b}\end{array}$ & Description of Framing \\
\hline & & & & & & & & & $\begin{array}{l}\text { bioreactor technology analogous } \\
\text { to the human body") }\end{array}$ \\
\hline Life Tech & 3 & 4 & 1 & 3 & $\begin{array}{c}11 / 10.28 \\
(1.1)\end{array}$ & $\begin{array}{l}\text { Hands are clasped together } \\
\text { behind the speaker's back for } \\
\text { most of the presentation. }\end{array}$ & $40 / 1379$ & 29 & $\begin{array}{l}\text { Extensive use of metaphors, } \\
\text { analogies and common business } \\
\text { idioms (e.g., "the width of a } \\
\text { human hair", "three routes to } \\
\text { market", "we already have a toe } \\
\text { in the water working with major } \\
\text { bio-pharmaceutical companies") }\end{array}$ \\
\hline
\end{tabular}

\section{Approach 3: The Demonstrative Approach (High use of gesture, Low use of figurative language)}

\begin{tabular}{|c|c|c|c|c|c|c|}
\hline Sleeptight & 43 & 9 & 8 & 8 & $\begin{array}{c}65 / 14.3 \\
(4.5)\end{array}$ & $\begin{array}{l}\text { Uses beat gestures throughout, } \\
\text { interspersed with ideational and } \\
\text { metaphoric gesture (e.g., both } \\
\text { hands positioned centrally and } \\
\text { together and then moved apart, } \\
\text { rotating hands slightly so that } \\
\text { palms are facing up upward in a } \\
\text { smooth movement to show the } \\
\text { concept of 'cash flow') }\end{array}$ \\
\hline
\end{tabular}

5.93

Rheology
$153 / 14.7$

(10.4)
Uses an extensive amount of

beat gestures throughout (e.g., right hand moves up and down at just above waist height with palm facing upward).
$8 / 1350$

Minimal use of figurative language, but extended use of single anecdote (the entrepreneur's own snoring problem) "speed up the time to market") 
TABLE 1 Study 1: Results of Gesture and Language Coding Type and Frequency of Gestures

Type and Frequency of Figurative Language

\begin{tabular}{|c|c|c|c|c|c|c|c|c|c|}
\hline Case & 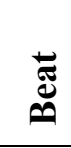 & 苂 & $\cdot \frac{e}{0}$ & $\sum_{\Sigma}^{\frac{1}{\pi}} \frac{e}{2}$ & $\begin{array}{c}\text { Total } \\
\text { Gestures/ } \\
\text { Minutes }^{\text {a }}\end{array}$ & Description of Gesturing & $\begin{array}{c}\text { Figurative } \\
\text { / Total } \\
\text { Words }\end{array}$ & $\begin{array}{l}\text { Proportion } \\
\text { Figurative }^{\text {b }}\end{array}$ & Description of Framing \\
\hline $\begin{array}{l}\text { Safe } \\
\text { Skins }\end{array}$ & 82 & 15 & 7 & 5 & $\begin{array}{c}109 / 10.02 \\
(10.9)\end{array}$ & $\begin{array}{l}\text { Uses gestures throughout, } \\
\text { combining beat (e.g., right hand } \\
\text { with palm facing upward move } \\
\text { up and down or side to side) and } \\
\text { ideational gestures (e.g., right } \\
\text { hand used to imitate pushing } \\
\text { down a door handle by making a } \\
\text { fist and rotating the fist in a } \\
\text { downward motion helping to } \\
\text { explain how product works) }\end{array}$ & $17 / 1587$ & 10.7 & $\begin{array}{l}\text { Specific use of common idioms } \\
\text { (e.g., "we are not jumping } \\
\text { through any specific legislative } \\
\text { hoops for this") }\end{array}$ \\
\hline $\begin{array}{l}\text { About } \\
\text { Waste } \\
\text { Water }\end{array}$ & 54 & 5 & 3 & 4 & $\begin{array}{c}66 / 10.18 \\
(6.6)\end{array}$ & $\begin{array}{l}\text { Uses gesture consistently } \\
\text { throughout, predominantly beat } \\
\text { gesture using the right hand } \\
\text { moving up and down with palm } \\
\text { sideways facing towards the } \\
\text { middle of the body. The left } \\
\text { hand often rests on the podium. }\end{array}$ & $21 / 1449$ & 14.5 & $\begin{array}{l}\text { Common business idioms } \\
\text { (“... and this is just a stepping } \\
\text { stone towards accessing a global } \\
\text { market") }\end{array}$ \\
\hline Ink Flow & 103 & 9 & 8 & 14 & $\begin{array}{c}134 / 13.6 \\
(9.8)\end{array}$ & $\begin{array}{l}\text { Gestures extensively throughout, } \\
\text { often using a beat gesture with } \\
\text { right hand in "chopping" motion } \\
\text { moving up and down and side to } \\
\text { side at chest height. }\end{array}$ & $38 / 2123$ & 17.9 & $\begin{array}{l}\text { Common business idioms (e.g., } \\
\text { "we have got distributors in } \\
\text { place now, we have them in } \\
\text { place in the US and in China...") }\end{array}$ \\
\hline
\end{tabular}

Approach 4: The Integrated Approach (High use of gesture, High use of figurative language)

\begin{tabular}{|c|c|c|c|c|c|c|c|c|}
\hline $\begin{array}{l}\text { Organ } \\
\text { Solutions }\end{array}$ & 215 & 11 & 14 & $\begin{array}{c}241 / 13.5 \\
(17.9)\end{array}$ & $\begin{array}{l}\text { Uses all forms of gestures } \\
\text { extensively throughout (e.g., left } \\
\text { hand moves upwards from waist } \\
\text { to shoulder height to show the } \\
\text { ability of the solution to } \\
\text { maintain transplant organs }\end{array}$ & $52 / 1512$ & 34.4 & $\begin{array}{l}\text { Extensive use of metaphors, } \\
\text { analogies and common business } \\
\text { idioms ("window of } \\
\text { opportunity", "the latest news } \\
\text { off the press is we will get...", } \\
\text { "need to grasp the opportunity of }\end{array}$ \\
\hline
\end{tabular}


TABLE 1 Study 1: Results of Gesture and Language Coding Type and Frequency of Gestures

Type and Frequency of Figurative Language

\begin{tabular}{|c|c|c|c|c|c|c|c|c|c|}
\hline Case & $\stackrel{\varpi}{\mathscr{E}}$ & 电 & 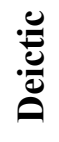 & 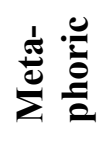 & $\begin{array}{l}\text { Total } \\
\text { Gestures/ } \\
\text { Minutes }^{\text {a }}\end{array}$ & Description of Gesturing & $\begin{array}{l}\text { Figurative } \\
\text { / Total } \\
\text { Words }\end{array}$ & $\begin{array}{l}\text { Proportion } \\
\text { Figurative }^{b}\end{array}$ & Description of Framing \\
\hline & & & & & & $\begin{array}{l}\text { "twice as long" in comparison to } \\
\text { rival products). }\end{array}$ & & & $\begin{array}{l}\text { the lapsing of patents and the } \\
\text { lack of noise in the market at this } \\
\text { point in time") }\end{array}$ \\
\hline $\begin{array}{l}\text { Power } \\
\text { Tidal }\end{array}$ & 119 & 9 & 7 & 6 & $\begin{array}{l}141 / 12.6 \\
(11.2)\end{array}$ & $\begin{array}{l}\text { Gestures almost continuously } \\
\text { throughout (e.g. left hand moves } \\
\text { from waist height to above the } \\
\text { speaker's head with hand flat } \\
\text { and palm facing the ground, } \\
\text { illustrating the turbines can be } \\
\text { customized and made larger). }\end{array}$ & $46 / 1341$ & 34.3 & $\begin{array}{l}\text { Extensive use of metaphors, } \\
\text { analogies and common business } \\
\text { idioms ("government has ring- } \\
\text { fenced a fund...", "the industry } \\
\text { is starting to catch onto this...", } \\
\text { "we expect to be switching on } \\
\text { the lights within two weeks") }\end{array}$ \\
\hline $\begin{array}{l}\text { Angel } \\
\text { Mobile }\end{array}$ & 59 & 8 & 18 & 9 & $\begin{array}{l}94 / 10.1 \\
(9.3)\end{array}$ & $\begin{array}{l}\text { Gestures continuously } \\
\text { throughout including an } \\
\text { extensive use of deictic gestures } \\
\text { to emphasize points and draw } \\
\text { the audience's attention to key } \\
\text { information in his speech. }\end{array}$ & $79 / 1600$ & 49.3 & $\begin{array}{l}\text { Extensive use of metaphors, } \\
\text { analogies and common business } \\
\text { idioms (e.g., "we have avoided } \\
\text { technical difficulties that got in } \\
\text { the way of making this work", } \\
\text { "to understand the difference just } \\
\text { consider a bookshop...", "...we } \\
\text { send the request to the } \\
\text { spontaneity engine...") }\end{array}$ \\
\hline $\begin{array}{l}\text { Tech } \\
\text { Ambition }\end{array}$ & 249 & 3 & 7 & 7 & $\begin{array}{l}266 / 15.2 \\
(17.5)\end{array}$ & $\begin{array}{l}\text { Uses extensive beat gestures } \\
\text { throughout. The right hand } \\
\text { "beats" up and down according } \\
\text { to the rhythm of the speech and } \\
\text { the upwards and downwards } \\
\text { movements became more } \\
\text { pronounced at particular points. }\end{array}$ & $36 / 1756$ & 20.5 & $\begin{array}{l}\text { Extensive use of metaphors, } \\
\text { analogies and common business } \\
\text { idioms (e.g., "it was a deliberate } \\
\text { tactic to get ourselves through } \\
\text { the initial phase...we will break } \\
\text { into profitability, indeed we are } \\
\text { already ahead...", "we are on } \\
\text { track for growth...") }\end{array}$ \\
\hline
\end{tabular}

\footnotetext{
${ }^{a}$ Figures in parenthesis are the number of gestures per minute of the pitch.

${ }^{\mathrm{b}}$ Proportion figurative refers to the number of figurative words per 1,000 words of the pitch.
} 
TABLE 2 Study 2: Means, Standard Deviations, and Correlations

\begin{tabular}{|c|c|c|c|c|c|c|c|c|c|c|c|}
\hline Variables, Sample 1 (n=124) & Mean & s.d. & 1 & 2 & 3 & 4 & 5 & 6 & 7 & 8 & 9 \\
\hline 1. Gender & .83 & .38 & & & & & & & & & \\
\hline 2. Age & 52.16 & 11.88 & $.18^{*}$ & & & & & & & & \\
\hline 3. Investment experience & 12.25 & 11.97 & $.21^{*}$ & $.42^{* *}$ & & & & & & & \\
\hline 4. Investor type & .22 & .41 & .08 & .00 & .00 & & & & & & \\
\hline 5. Figurative language & .49 & .50 & .14 & -.04 & .07 & -.09 & & & & & \\
\hline 6. Gesture & .49 & .50 & .09 & .06 & .01 & -.03 & .13 & & & & \\
\hline 7. Mental imagery & 3.35 & 1.41 & .02 & .08 & -.03 & -.06 & .05 & $.22^{*}$ & $(.86)$ & & \\
\hline 8. Passion & 2.19 & 1.00 & .11 & .00 & .08 & -.07 & $.37^{* *}$ & $.65^{*}$ & $.33^{* *}$ & $(.92)$ & \\
\hline 9. Preparedness & 3.34 & .89 & .01 & -.02 & -.07 & -.11 & .08 & .08 & $.38^{* *}$ & $.25^{* *}$ & $(.87)$ \\
\hline 10. Propensity to invest ${ }^{a}$ & .00 & .91 & .01 & .07 & -.08 & .04 & .00 & $.22^{* *}$ & $.56^{* *}$ & $.31^{* *}$ & $.58^{* *}$ \\
\hline
\end{tabular}

\begin{tabular}{lrlrrrrrrr} 
Variables, Sample $2(\mathrm{n}=\mathbf{1 8 0})$ & Mean & s.d. & $\mathbf{1}$ & $\mathbf{2}$ & $\mathbf{3}$ & $\mathbf{4}$ & $\mathbf{5}$ & $\mathbf{6}$ & $\mathbf{7}$ \\
\hline 1. & .42 & .50 & & & & & & &
\end{tabular}

1. Gender

$\begin{array}{rrr}.42 & .50 & \\ 20.07 & 2.87 & .05 \\ .50 & .50 & .02\end{array}$

2. Age

$\begin{array}{rrr}.50 & .02 & .03\end{array}$

3. Figurative language

$\begin{array}{llll}.50 & .50 & -.16^{*} \quad .11\end{array}$

4. Gesture

$\begin{array}{lllllll}4.30 & 1.12 & .02 & -.01 & .09 & .15^{*} & (.88)\end{array}$

5. Mental imagery

$\begin{array}{lllllll}2.63 & .89 & .05 & .16^{*} & .18^{*} & .41^{* *} & .37^{* *}\end{array}$

6. Passion

$3.82 \quad .72$

$\begin{array}{rr}-.07 & -.02 \\ -.01 & -.06\end{array}$

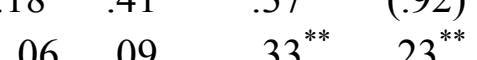

7. Preparedness

.00

$.01 \quad-.06$

$.13 .20^{* *} \quad .46^{* *} \quad .36^{* *} \quad .54^{* *}$

Notes

Coefficient alphas are on the diagonal in parentheses.

Gender: $0=$ female, $1=$ male. Investor type: $0=$ low value investors, $1=$ high value investors. Framing: $0=$ low framing, $1=$ high framing. Gesture: $0=$ low gesture, $1=$ high gesture.

${ }^{\mathrm{a}}$ Standardized

${ }^{*} p<0.05,{ }^{* *} p<0.01$ 
TABLE 3 Study 2: Group Means and Standard Deviations

\begin{tabular}{lcc}
\hline & \multicolumn{2}{c}{ Propensity to Invest $^{\mathbf{a}}$} \\
\cline { 2 - 3 } Condition & Sample 1 (n=124) & Sample 2 (n=180) \\
\hline Low figurative language, low gesture & -.18 & -.23 \\
& $(1.01)$ & $(.78)$ \\
Low figurative language, high gesture & .25 & .01 \\
& $(.62)$ & $(.81)$ \\
High figurative language, low gesture & -.21 & -.10 \\
High figurative language, high gesture & $(.98)$ & $(.93)$ \\
& .18 & .32 \\
& $(.89)$ & $(.84)$ \\
\hline
\end{tabular}

Note

Standard deviations are in parentheses.

${ }^{\mathrm{a}}$ Standardized

TABLE 4 Study 2 Results: Mental Imagery and Passion Mediating the Effects of Gesture on Propensity to Invest

\begin{tabular}{|c|c|c|c|c|c|c|}
\hline & \multicolumn{3}{|c|}{ Sample 1} & \multicolumn{3}{|c|}{ Sample 2} \\
\hline & \multirow[b]{2}{*}{$B$} & \multicolumn{2}{|r|}{$95 \%$} & \multirow[b]{2}{*}{$B$} & \multicolumn{2}{|r|}{$95 \%$} \\
\hline & & $S E$ & LLCI-ULCI & & $S E$ & LLCI-ULCI \\
\hline Constant & $-1.36^{* * *}$ & .21 & $-1.78,-.96$ & $-1.81^{* * *}$ & .24 & $-2.29, \quad-1.34$ \\
\hline Passion & .11 & .09 & $-.08, .29$ & $.19^{*}$ & .07 & $.04, .33$ \\
\hline Mental imagery & $.33^{* * *}$ & .05 & $.23, .43$ & $.29^{* * *}$ & .05 & $.19, .40$ \\
\hline Gesture & .06 & .18 & $-.29, \quad .42$ & .10 & .12 & $-.14, \quad .34$ \\
\hline$R^{2}$ & & & .33 & & & .26 \\
\hline$F(d f)$ & & & $19.48^{* * *}$ & & & $20.49^{* * *}$ \\
\hline & & & $(3,120)$ & & & $(3,176)$ \\
\hline
\end{tabular}

Note: $B=$ unstandardized regression coefficient; $S E=$ standard error. $L L C I-U L C I=$ lower level confidence intervalupper level confidence interval.

$* p<.05, * * p<.01, * * * p<.001$ 
TABLE 5 Study 2 Results: Bootstrapped Indirect Effects of Gesture on Propensity to Invest through Mental Imagery and Passion

\begin{tabular}{|c|c|c|c|c|c|c|c|c|}
\hline & \multicolumn{4}{|c|}{ Sample 1} & \multicolumn{4}{|c|}{ Sample 2} \\
\hline & $\begin{array}{l}\text { Indirect } \\
\text { Effects }\end{array}$ & $\begin{array}{c}95 \% \\
\text { LLCI- } \\
\text { ULCI }\end{array}$ & $\begin{array}{l}\text { Direct } \\
\text { Effects }\end{array}$ & $\begin{array}{c}\text { Total } \\
\text { Effects }\end{array}$ & $\begin{array}{l}\text { Indirect } \\
\text { Effects }\end{array}$ & $\begin{array}{c}\text { 95\% } \\
\text { LLCI-ULCI }\end{array}$ & $\begin{array}{l}\text { Direct } \\
\text { Effects }\end{array}$ & $\begin{array}{c}\text { Total } \\
\text { Effects }\end{array}$ \\
\hline Passion & $\begin{array}{l}.14 \\
(.12)\end{array}$ & $-.09, \quad .39$ & & & $\begin{array}{l}.13 \\
(.06)\end{array}$ & $.04, .27$ & & \\
\hline $\begin{array}{l}\text { Mental } \\
\text { imagery }\end{array}$ & $\begin{array}{l}.20 \\
(.09)\end{array}$ & $.04, \quad .39$ & & & $\begin{array}{l}.10 \\
(.06)\end{array}$ & $.01, \quad .24$ & & \\
\hline Gesture & & & $\begin{array}{c}.06 \\
(.18)\end{array}$ & $\begin{array}{l}.40 \\
(.16)\end{array}$ & & & $\begin{array}{l}.10 \\
(.12)\end{array}$ & $\begin{array}{l}.33 \\
(.13)\end{array}$ \\
\hline
\end{tabular}

Note: Standard errors are in parentheses (standard errors for indirect effects are bootstrapped). $L L C I-U L C I=$ lower level confidence interval-upper level confidence interval.

TABLE 6 Study 2 Results: Bootstrapped Conditional Indirect Effects of Gesture on Propensity to Invest through Mental Imagery and Passion

\begin{tabular}{|c|c|c|c|c|c|c|}
\hline & \multicolumn{3}{|c|}{ Sample 1} & \multicolumn{3}{|c|}{ Sample 2} \\
\hline & $\begin{array}{l}\text { Indirect } \\
\text { Effects }\end{array}$ & SE & $\begin{array}{c}95 \% \\
\text { LLCI-ULCI }\end{array}$ & $\begin{array}{l}\text { Indirect } \\
\text { Effects }\end{array}$ & SE & $\begin{array}{c}95 \% \\
\text { LLCI-ULCI }\end{array}$ \\
\hline \multicolumn{7}{|l|}{ Mental imagery } \\
\hline Low figurative language & .11 & .08 & $.00, .31$ & .04 & .04 & $-.01, \quad .17$ \\
\hline High figurative language & .28 & .11 & $.08, \quad .52$ & .14 & .08 & $.01, \quad .32$ \\
\hline \multicolumn{7}{|l|}{ Passion } \\
\hline Low figurative language & .37 & .20 & $.02, .82$ & .06 & .09 & $-.11, .26$ \\
\hline High figurative language & .08 & .14 & $-.20, \quad .37$ & .19 & .07 & $.06, .34$ \\
\hline
\end{tabular}


(a) Metaphoric gesture representing the ability of the entrepreneur to cover the entire market. In this gesture, widening of the distance between the hands connotes expanded market coverage.

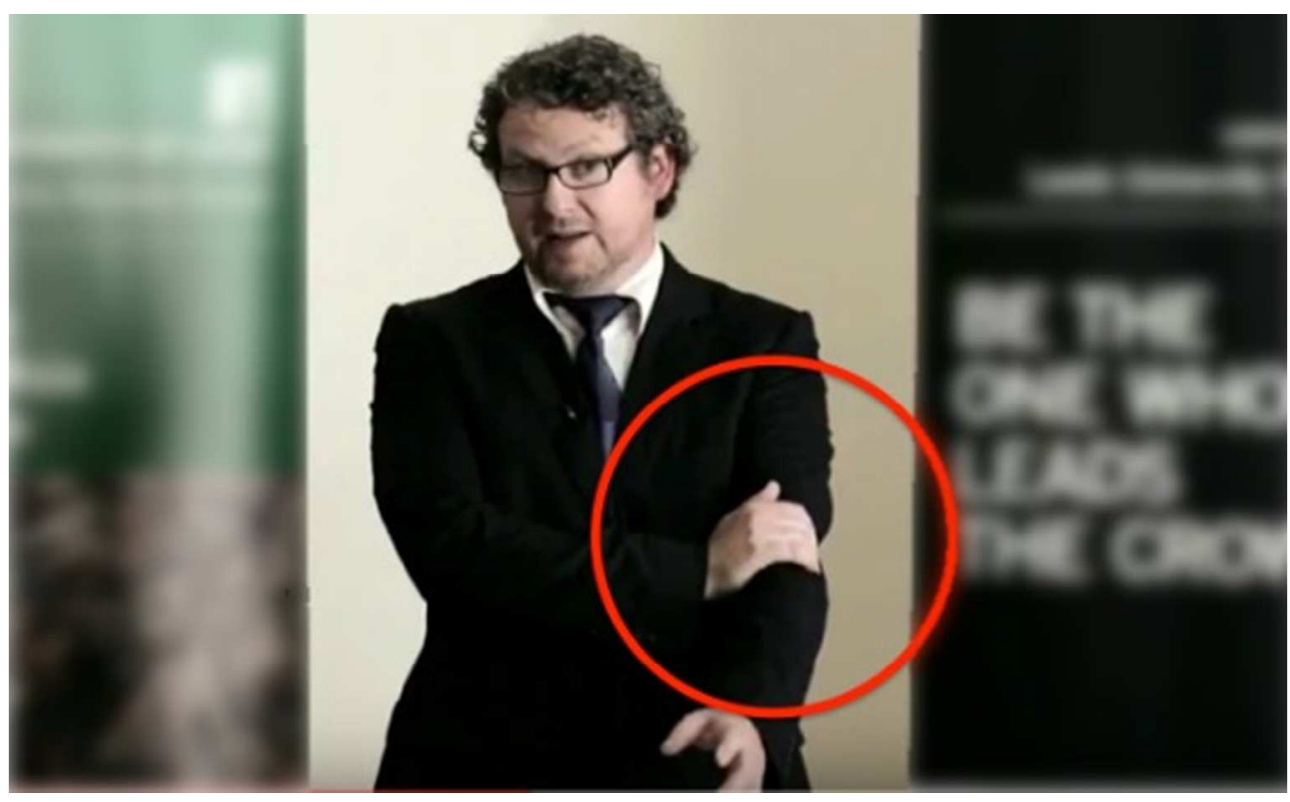

(b) Iconic gesture illustrating product usage. This gesture refers to a physical object (the treatment device) and its placement on the body (compressing an injured joint). 


\section{FIGURE 2 Study 2 Results: Moderated Mediation Model of the Effects of Gesturing on} Propensity to Invest

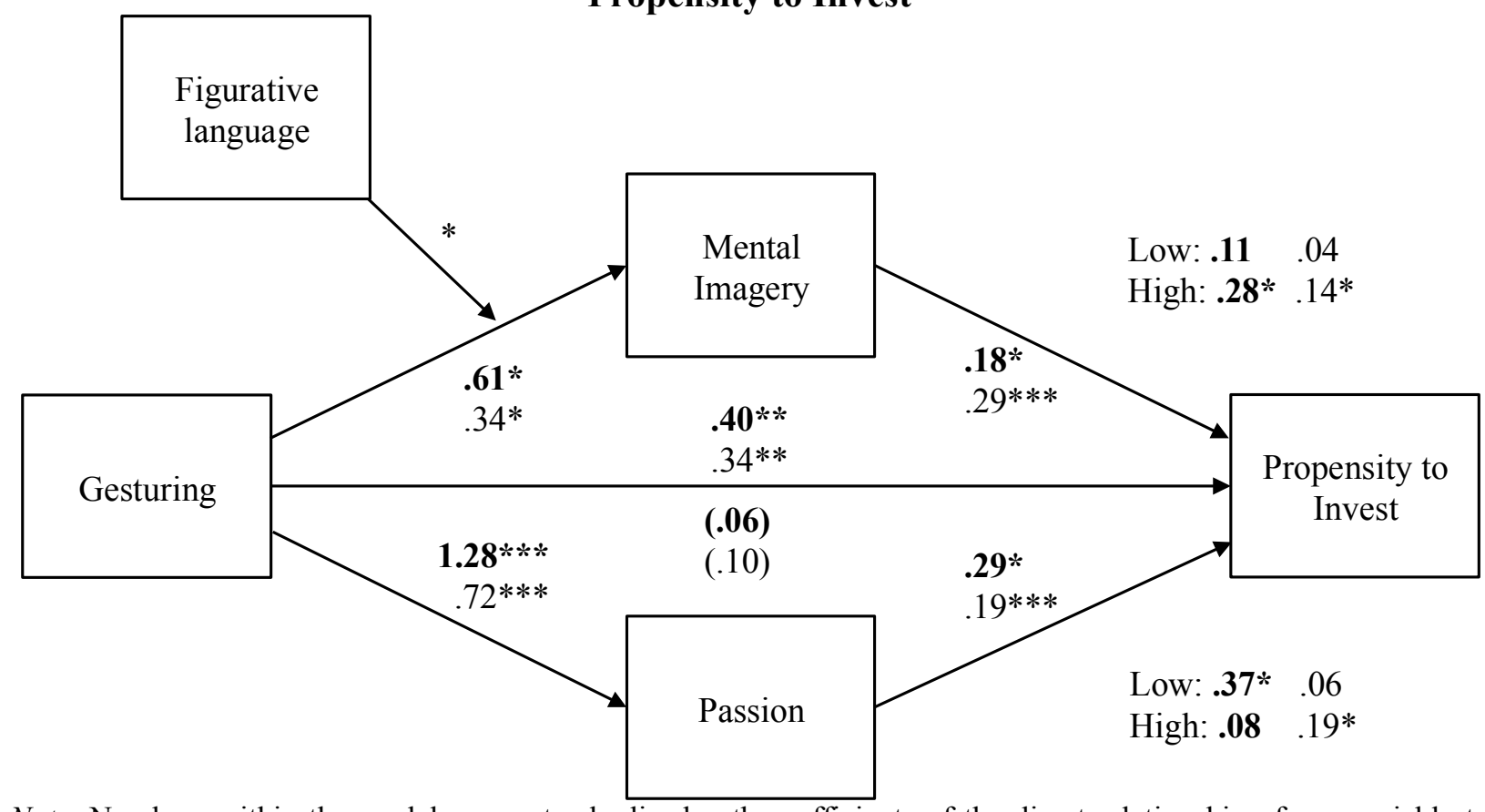

Note: Numbers within the model are unstandardized path coefficients of the direct relationship of one variable to another. Numbers outside the model are the conditional indirect effects of gesturing on propensity to invest through mental imagery and perceived passion. Low denotes the indirect effects at low levels of figurative language, whereas High denotes the indirect effects at high levels of figurative language. Finally, the numbers in parentheses below the path for the direct effect of gesturing on propensity to invest are the effects of gesturing after accounting for the mediators. Sample 1 results are in bold text and sample 2 results are in regular text.

$* p<.05, * * p<.01, * * * p<.001$.

\section{Biographies}

Jean Clarke is a professor of entrepreneurship and organization at Emlyon Business School, France. She received her PhD from the University of Leeds, UK. Her research explores how language and bodily displays are used in entrepreneurial communication as a means to develop legitimacy and access resources.

Joep Cornelissen is professor of corporate communication and management at Rotterdam School of Management, Erasmus University. He received his PhD from the Manchester Metropolitan University. His research focuses on the role of corporate and managerial communication in the context of innovation, entrepreneurship and change, and on social evaluations of the legitimacy and reputation of start-up and established firms.

Mark Healey is Senior Lecturer (Associate Professor) in Strategic Management at Alliance Manchester Business School, University of Manchester. He received his PhD in Management Sciences from the University of Manchester Institute of Science and Technology (UMIST). His research focuses on cognition and emotion in organizations, particularly their role in strategic adaptation. 